\title{
A role for reward valuation in the serotonergic modulation of impulsivity
}

\author{
Stephanie S. Desrochers ${ }^{1} \cdot$ Emma K. Lesko $^{1} \cdot$ Valerie M. Magalong $^{2,3} \cdot$ Peter D. Balsam $^{2,3} \cdot$ Katherine M. Nautiyal $^{1}$
}

Received: 27 April 2021 / Accepted: 22 July 2021 / Published online: 14 August 2021

(c) The Author(s) 2021

\begin{abstract}
Rationale Impulsive behavior is a deleterious component of a number of mental health disorders but has few targeted pharmacotherapies. One contributing factor to the difficulty in understanding the neural substrates of disordered impulsivity is the diverse presentations of impulsive behavior. Defining the behavioral and cognitive processes which contribute to different subtypes of impulsivity is important for understanding the neural underpinnings of dysregulated impulsive behavior. Methods Using a mouse model for disordered impulsivity, our goal was to identify behavioral and cognitive processes that are associated with increased impulsivity. Specifically, we were interested in the facets of impulsivity modulated by serotonin signaling. We used mice lacking the serotonin $1 \mathrm{~B}$ receptor $\left(5-\mathrm{HT}_{1 \mathrm{~B}} \mathrm{R}\right)$ and measured different types of impulsivity as well as goal-directed responding, extinction, habitual-like behavior, cue reactivity, and reward reactivity.

Results Mice lacking expression of 5- $\mathrm{HT}_{1 \mathrm{~B}} \mathrm{R}$ had increased levels of impulsive action, goal-directed responding, and motivation, with no differences seen in rate of extinction, development of habitual behavior, delay discounting, or effort-based discounting. Interestingly, mice lacking $5-\mathrm{HT}_{1 \mathrm{~B}} \mathrm{R}$ expression also showed an overall increase in the choice of higher value rewards, increased hedonic responses to sweet rewards, and responded more for cues that predict reward. We developed a novel paradigm to demonstrate that increasing anticipated reward value could directly increase impulsive action. Furthermore, we found that $5-\mathrm{HT}_{1 \mathrm{~B}} \mathrm{R}$ KO-induced impulsivity could be ameliorated by decreasing the reward value relative to controls, suggesting that the increased 5- $\mathrm{HT}_{1 \mathrm{~B}} \mathrm{R}$-associated impulsive action may be a result of increased reward valuation.

Conclusions Taken together, these data show that the effects of serotonin on impulsive action are mediated through the modulation of hedonic value, which may alter the reward representations that motivate action. Overall, this data supports a role for reward value as an important substrate in impulsive action which may drive clinically relevant increases in impulsivity.
\end{abstract}

Keywords Reward valuation $\cdot$ Serotonergic modulation $\cdot$ Impulsivity $\cdot 5$-HT1B

\section{Introduction}

Impulsivity is an important component of daily life, but can lead to many deleterious outcomes such as making unhealthy eating decisions or excessive online shopping. It is also a core component of a number of psychiatric disorders including attention deficit disorder, alcohol and substance use

Katherine M. Nautiyal

katherine.nautiyal@dartmouth.edu

1 Department of Psychological and Brain Sciences, Dartmouth College, Hanover, NH 03755, USA

2 Department of Psychology, Barnard College and Columbia University, New York, NY 10027, USA

3 Department of Psychiatry, Columbia University, New York, NY 10032, USA disorders, and gambling disorder (Dalley and Robbins 2017; MacKillop et al. 2016; Robbins et al. 2012). Treatment options to decrease impulsivity are limited, and those that exist are not targeted to impulsive behavior. One underlying issue in the development of approaches to reduce impulsive behavior lies within the complexity of the broad construct of impulsivity. Individual facets of what is broadly referred to as impulsive behavior, for example, impulsive action (e.g., acting on a whim) and impulsive choice (e.g., wanting immediate gratification), are likely mediated by different behavioral/cognitive processes with different neurobiological substrates (Bari and Robbins 2013; Nautiyal et al. 2017; Robbins et al. 2012; Winstanley et al. 2004a). Though, some argue against the use of the term impulsivity at all given the divergence and independence of its latent factors, in favor of more specific labels which have internally consistent 
behavioral and neurobiological substrates (Strickland and Johnson 2020). Furthermore, processes such as reward valuation, compulsivity, motivation, attention deficits, noveltyseeking, and anxiety have all been associated with some aspects of impulsivity using trait-level behavioral measures in humans (particularly in psychiatric populations) and in preclinical models (Chamorro et al. 2012; Dalley et al. 2011; Diergaarde et al. 2008; Ferland et al. 2014; Lovic et al. 2011; Moustafa et al. 2017; Weafer et al. 2014). Understanding how these behavioral and cognitive substrates are causally associated with different components of impulsive behavior will lead to an understanding of the behavioral/cognitive scaffolding and associated underlying neural circuits which lead to dysregulated impulsivity.

Ours and others' previous work has examined how different dimensions of impulsivity can be dissociated, behaviorally and biologically (Dalley and Robbins 2017; Nautiyal et al. 2017; Winstanley et al. 2004b; Zeeb et al. 2016, 2013). Specifically, impulsive action, characterized by the reduced ability to withhold or delay responses, is independent from impulsive choice, which includes an exaggerated discounting of future or risky rewards. While many studies have focused on the role of dopamine in the modulation of impulsivity, serotonin signaling is particularly relevant when focusing on dissociation of the neurobiology of impulsive choice from impulsive action. Manipulation of serotonin signaling in humans and rodents supports its role in modulating impulsive action specifically (Fletcher et al. 2007; Higgins et al. 2016; Winstanley et al. 2004a; Worbe et al. 2014). The mechanisms of these effects are likely through a number of the 14 serotonin receptors including $5-\mathrm{HT}_{1 \mathrm{~B}}$, $5-\mathrm{HT}_{2 \mathrm{~A}}$, and $5-\mathrm{HT}_{2 \mathrm{C}}$. We previously reported that mice lacking the 5- $\mathrm{HT}_{1 \mathrm{~B}}$ receptors show increased impulsive action, but not impulsive choice (Brunner and Hen 1997; Nautiyal et al. 2015, 2017; Pattij et al. 2003). Interestingly, in humans, $5-\mathrm{HT}_{1 \mathrm{~B}} \mathrm{R}$ has also been implicated in disorders which present with dysregulated impulsivity, such as substance use and gambling disorders. Cocaine-dependent individuals had reduced 5- $\mathrm{HT}_{1 \mathrm{~B}} \mathrm{R}$ activation compared to controls (Matuskey et al. 2014), and single-nucleotide polymorphisms in htrlb were associated with cocaine, alcohol, and heroin abuse (Cao et al. 2013). In preclinical models, genetic knockout of 5- $\mathrm{HT}_{1 \mathrm{~B}} \mathrm{R}$ caused increases in cocaine self-administration in mice (Rocha et al. 1998), and administration of a 5- $\mathrm{HT}_{1 \mathrm{~B}} \mathrm{R}$ agonist decreased behavior motivated by both cocaine and sucrose rewards (Acosta et al. 2005).

Serotonin signaling could act through several cognitive and behavioral mechanisms which may promote difficulty withholding responses (elevated impulsive action). While it is common to attribute this type of impulsivity to a deficit in inhibitory control, behavioral action is a product of both inhibitory and excitatory processes. Given intact inhibitory control mechanisms, an exaggerated representation of reward value may also make "holding back" difficult due to increased drive, resulting in increased impulsivity. The representation of reward value that motivates behavioral responding arises from experiences with the current hedonic value of rewards (Balleine and Dickinson 1998; Dickinson and Balleine 1994; 2002). When response-outcome contingencies are learned, the likelihood of responding is guided by the incentive value of the outcome, which can be seen in the hedonic reaction (Dickinson and Balleine 1995). For example, when subjects are hungry, food rewards have greater value than when subjects are sated, and thus hedonic reactions are diminished. When the expected reward value is lowered, motivation is also reduced. While the hedonic reactions to reward referred to as "liking" and the motivational processes that energize behavior referred to as "wanting " can be dissociated, wanting is generally directed at available outcomes that are liked (Berridge et al. 2009, 1989; Smith and Berridge 2007; Ward et al. 2012). Here we refer to the increased responding for an appetitive outcome as reward reactivity to include components of both liking and wanting.

Both increased reward reactivity and increased impulsivity are found in patients with substance use disorders, and potentially represent risk factors for the development of addictive disorders (Crane et al. 2018; Dissabandara et al. 2014; Jonker et al. 2014; Kamarajan et al. 2015; VerdejoGarcía et al. 2008). In this framework, substance use disorders may arise from deficits in inhibitory control, but also from exaggerated hedonic valuation and/or through increased incentive salience, as in the Incentive-Sensitization Theory (Berridge and Robinson 2016). It is possible that the contribution of the $5-\mathrm{HT}_{1 \mathrm{~B}} \mathrm{R}$ to drug-seeking behaviors is due to the modulation of hedonic reactions to drugs, at least in part. Reward reactivity has also been implicated in gambling disorder, with increased pleasure derived from winning potentially promoting the escalation of the behavioral addiction (Gaher et al. 2015; Jimenez-Murcia et al. 2017). Additionally, in gambling disorder patients, levels of $5-\mathrm{HT}_{1 \mathrm{~B}} \mathrm{R}$ in brain regions associated with reward processing, including the ventral striatum, correlated with the severity of the disorder (Potenza et al. 2013). These considerations suggest the possibility that $5-\mathrm{HT}_{1 \mathrm{~B}} \mathrm{R}$ may impact impulsivity through changes in hedonic reactions and thus alter the representation of the value of a reward that motivates behavioral action.

The goal in the present studies was first to investigate what behavioral/cognitive processes, such as reward valuation, contribute to deficits in behavioral inhibition, and second to understand which process mediates the effect of serotonin on impulsive action. Specifically, we explored the effect of $5-\mathrm{HT}_{1 \mathrm{~B}} \mathrm{R}$ on potential substrates of impulsivity including goal-directed responding, motivation, habitual-like responding, and hedonic responding. While each of these can be conceptualized as unique behavioral phenotypes with 
distinct neural substrates, we focused on how alterations in impulsive action could potentially be subserved by changes in these processes. We specifically tested the hypothesis that the influence of serotonin on impulsivity is mediated by effects on the valuation of reward outcome. Additionally, by assessing these phenotypes in a mouse model for pathological impulsivity with deficits limited to impulsive action (absence of $5-\mathrm{HT}_{1 \mathrm{~B}} \mathrm{R}$ ), we were also able to determine how associated behavioral mechanisms are related to different domains of impulsivity (Winstanley et al. 2004a). Coming to a better understanding of the specific neural and behavioral substrates of different dimensions of impulsivity will help us understand how these components combine to generate dysregulated impulsivity in psychiatric disorders.

\section{Methods}

\section{Mice}

Animals were bred in the Center for Comparative Medicine at Dartmouth College, or in the Department of Comparative Medicine at the New York State Psychiatric Institute. All mice were weaned at postnatal day (PN) 21 into cages of 2-5 same sex littermates on a 12:12 light-dark cycle, and maintained on ad lib chow until experimental operant behavioral testing began at 10-14 weeks. The floxed tetO1B mouse model was used to generate groups of mice lacking expression of $5-\mathrm{HT}_{1 \mathrm{~B}} \mathrm{R}$ through crosses to a $\beta$ Actin-tTS mouse line (tetO1B $+/+$ females crossed to tetO1B $+/+:: \beta$ ActintTS + males), as previously reported (Nautiyal et al. 2015). In the validation of the Variable Value Go/No-Go paradigm, only tetO1B $+/+$ control mice were used. In all other studies, tetO1B:: $\beta$ Actin-tTS + mice and their littermate controlstetO1B:: $\beta$ Actin-tTS - mice were used. For the adult rescue groups, tetO1B:: $\beta$ Actin-tTS + mice were fed chow with doxycycline (DOX; $40 \mathrm{mg} / \mathrm{kg}$, BioServ) beginning at PN60 in order to rescue expression of the $5-\mathrm{HT}_{1 \mathrm{~B}} \mathrm{R}$ in the adult mouse, as previously validated and reported (Nautiyal et al. 2015). All procedures were approved by the Institutional Animal Care and Use Committees of the New York State Psychiatric Institute or Dartmouth College.

A summary table of the mice used in these experiments is provided in Table $\mathrm{S} 1$. One group of male $(N=23)$ and female $(N=35)$ mice were used in goal-directed behavior, extinction, concurrent choice, and satiety-induced devaluation. One mouse was excluded from progressive ratio due to technical issues, and one mouse died prior to the test, resulting in $N=22$ males and $N=34$ females included in the final analysis for the progressive ratio. Subsets of the total group were used in satiety-induced devaluation experiments (males $N=23$, females $N=18$ ) and Go/No-Go and delay discounting (males $N=12$, females $N=8$ ). One mouse was excluded from delay discounting due to not meeting criteria (see delay discounting methods below). A separate group of mice was used to test effort-based discounting (males $N=7$, females $N=14$ ). Two mice were excluded from effort-based discounting due to not meeting criteria. A group of mice ( $N=19$, all female) were used to test free consumption of evaporated milk diluted at different concentrations. Additional groups of naïve mice were used in the lickometer (males $N=6$, females $N=5$ ) and Pavlovian-toinstrumental transfer (PIT; males $N=6$, females $N=9$ ) studies. One mouse was excluded from the PIT study because of a failure to lever press. An additional naïve group of 12 control mice (males $N=7$, females $N=5$ ) was used for the validation study of the novel Variable Value Go/No-Go paradigm. Finally, for the study of the role of the $5-\mathrm{HT}_{1 \mathrm{~B}} \mathrm{R}$ in the Variable Value Go/No-Go paradigm, an additional group of naïve mice (males $N=14$, females $N=7$ ) was used to test the effect of 5-HT ${ }_{1 \mathrm{~B}} \mathrm{R}$ expression. Three mice were removed due to not meeting criteria during lever training. A subset of the animals from this experiment (males $N=13$, females $N=5$ ) were used to examine the effect of $5-\mathrm{HT}_{1 \mathrm{~B}} \mathrm{R}$ expression on chow consumption.

\section{Operant behavioral apparatus}

Operant studies were conducted in eight identical chambers (Med Associates, St. Albans, VT) individually enclosed in ventilated isolation boxes. Each operant chamber consisted of stainless steel modular walls, and stainless steel bar floors. Each chamber contained a noseport receptacle for the delivery of liquid reward by a dipper ( $0.02 \mathrm{ml}$ cup volume), with head entry detected by an infrared beam break detector. On either side of the noseport, the chamber contained two ultra-sensitive retractable stainless steel levers placed $2.2 \mathrm{~cm}$ above the chamber floor. In paradigms in which only one of the two levers was used, the lever was counterbalanced across mice and remained the same throughout all paradigms. There were LEDs located above each lever, and a houselight and speaker located on the upper portion of the wall opposite the levers. A computer equipped with MEDPC IV (Med Associates Inc., St Albans, VT) computer software delivered stimuli and collected behavioral data.

\section{Operant behavioral training}

Operant training and testing were run 5-7 days a week. Mice were maintained at approximately $90 \%$ of their freefeeding weight. Water was provided ad libitum throughout the experiment. Undiluted evaporated milk was used as the reward for all operant studies in MedAssociates chambers. All mice were first trained to retrieve an evaporated milk reward through head entry into the receptacle, and then trained to press one of the two retractable levers to receive 
the evaporated milk reward on a continuous reinforcement (CRF) schedule. Daily sessions ended when mice received a maximum of 60 rewards, or after 60 min elapsed if the maximum had not been reached. Mice were trained until the criterion of 55 lever presses in a 60-min session was reached. The mice were then trained on a random ratio (RR) schedule of escalating effort requirements (3 days of RR-5, 3 days of RR-10, 3 days of RR-20). The data from the last day on each schedule was analyzed. Subsequently, they were tested in extinction trials, concurrent choice, satiety-induced devaluation (a subset), and then progressive ratio. A subset of mice were then tested in Go/No-Go and delay discounting paradigms.

\section{Progressive ratios of responding}

Following random ratio testing, mice were tested on a progressive ratio (PR) schedule for three consecutive days. A PRx 2 schedule was used in which the number of lever presses required to receive a reward doubled following each reward. The session ended following either $2 \mathrm{~h}$, or a 3-min period in which no lever presses were recorded (Drew et al. 2007). The total number of lever presses were summed over the session. One mouse was excluded from analysis due to technical problems with the operant box.

\section{Extinction testing}

Mice were exposed to an RR-20 schedule of reinforcement for 3 days, before being tested in 3 consecutive days of extinction training. Mice were placed in the operant box with the lever extended; however, rewards were not administered. Lever presses and head entries were recorded for the duration of the 60-min extinction sessions.

\section{Concurrent choice}

Following 3 days of RR-20 schedule of reinforcement, mice were placed in the operant box on each of 2 days with either freely available chow pellets or freely available evaporated milk in a cell culture dish. The lever of the operant box was also extended and was rewarding the mice with evaporated milk on a RR-20 schedule. These chow and milk conditions were counterbalanced across mice over the 2 days separated by a no choice RR-20 schedule day. Chow pellets and the dish of evaporated milk were weighed before and after the test session. Lever presses and head entries were recorded during the 60-min session.

\section{Satiety-induced devaluation}

Following 3 days of RR-20 schedule of reinforcement, mice were prefed either chow or evaporated milk on each of 2 days, counterbalanced across mice. Mice were placed individually in a holding cage similar to their home cage for $1 \mathrm{~h}$, and were free to consume an unlimited amount of either chow or evaporated milk presented in a cell culture dish. Chow pellets, the dish of evaporated milk, and the mice were weighed before and after the hour-long prefeeding session. Mice were then placed in the operant box and allowed to lever press for a RR-20 schedule of reinforcement. Lever presses and head entries were recorded during the 60-min session.

\section{Food consumption}

Mice were temporarily housed in individual cages for measurement of food consumption with ad lib access to water. Mice were placed on the food restriction protocol $48 \mathrm{~h}$ prior to testing in the "food restricted" state testing, to mimic the food restriction state of the operant paradigms which consisted of $1.5 \mathrm{~h}$ free access to chow daily. Twenty-four hours following the $1.5 \mathrm{~h}$ free access, chow was returned to mice and intake was measured at $1 \mathrm{~h}, 3 \mathrm{~h}$, and $24 \mathrm{~h}$ time points. Following this $24 \mathrm{~h}$ ad lib period, mice continued to have free access to chow for an additional $48 \mathrm{~h}$ prior to "sated" state testing, when intake was recorded for a $24-h$ period.

\section{Go/No-Go}

Mice were trained and tested as previously described (Nautiyal et al. 2015). Briefly, following training on Go Trials, mice were presented with 7 daily sessions consisting of 30 discrete Go trials and 30 No-Go trials which were pseudorandomly presented across blocks of 10 trials with a variable ITI averaging $45 \mathrm{~s}$. In No-Go trials, the lever was presented simultaneously with 2 cues (the house lights turning off, and a small LED light above the lever turning on). A lever press during the 5-s trial caused the lever to retract, the house lights to turn on, the LED light to turn off, and a new ITI to begin without any reward for that trial. A lack of presses during the 5-s trial resulted in a reward presentation. The impulsivity index was calculated by subtracting the proportion of correct No-Go trials from the proportion of correct Go trials.

\section{Delay discounting}

Mice were trained and tested as previously described (Nautiyal et al. 2017). Briefly, following training mice were presented with two levers for which presses resulted in either small or large $(3 \times$ volume $)$ rewards. The large reward was 
assigned to the lever which was initially least preferred by the mice, and remained consistent throughout the paradigm. Each daily session began with 10 forced choice trials (five on each lever randomly distributed) to ensure a minimum experience with each lever in each session, before presentation of 20 experimental choice trials. Mice were trained in 14 sessions with no delays on either lever. One mouse was eliminated because it did not meet the criteria of greater than $25 \%$ preference for the large lever averaged over the last 3 sessions. Subsequently, a delay was introduced after the large reward lever was pressed, before the reward was presented. There was no delay for the small reward, and time delays for the large reward $(0,2,4,6,8$, or $10 \mathrm{~s})$ were presented in separate sessions with 3 days for each time delay, in ascending delay order. Data were used from the last session of each time delay. A linear equation was fit to the preference data for each mouse over all delays, and the slope, intercept, and indifference point (imputed delay at $50 \%$ preference) were calculated from the linear regression.

\section{Effort discounting}

Mice were initially trained as described for the delay discounting paradigm by presenting two levers for which presses resulted in either small or large ( $3 \times$ volume) rewards. The large reward was assigned to the lever which was initially least preferred by the mice, and remained consistent throughout the paradigm. Each daily session began with 10 forced choice trials (five on each lever randomly distributed) to ensure a minimum experience with each lever in each session, before presentation of 20 experimental choice trials. Mice were trained in 14 sessions, after which two mice were eliminated because they did not meet the criteria of $>25 \%$ preference for the large lever averaged over the last 3 sessions. Subsequently, the fixed ratio (FR) schedule was increased from FR 1 for the large reward lever, with 3 days at each of the follow schedules: FR2, FR4, FR8, FR16, FR24, and FR32. The small reward lever remained at the FR1 schedule throughout the paradigm. Any single press to the small reward lever resulted in presentation of the small reward and termination of the trial. Percent preference for the large reward was calculated as the percentage of choice trials in which the large reward was obtained. Data from the last session at each FR schedule are presented and used for statistical analysis.

\section{Consumption of varied value rewards}

Prior to testing in this paradigm, mice were previously exposed to evaporated milk in both consumption tests and 13 weeks of operant behavioral testing under food restriction (as described above) rewarded with $100 \%$ evaporated milk in a variety of reinforcement paradigms (data not shown).
For the reward testing, mice were placed individually in a cage and given 5-min free access to a small cell culture dish (Falcon, $35 \mathrm{~mm} \times 10 \mathrm{~mm}$ ) with varying concentrations of evaporated milk in a separate clean cage identical to their home cage. Milk concentration was varied across 5 days of testing, with $33 \%, 66 \%, 100 \%, 66 \%$, and $33 \%$ on each day respectively (data was only analyzed for first 3 days because of anchoring effects on the descending concentration presentation). Mice were weighed immediately before and after testing to determine milk consumption during the session. Because of the potential inaccuracies in weighing the dishes due to milk spillage or bedding being pushed into the dishes, change in mouse weight was used to assay consumption over this short 5-min timeframe.

\section{Lickometer}

A Davis Rig 16-bottle Lickometer (Med Associates MEDDAV-160 M) was used to test the effect of $5-\mathrm{HT}_{1 \mathrm{~B}} \mathrm{R}$ expression on reward reactivity to various concentrations of sucrose in sated and restricted conditions as described previously (Ostlund et al. 2013). Mice were water restricted for 5 days of initial training, during which mice were placed individually in the apparatus and allowed to drink water for $30 \mathrm{~min}$ from the spout which recorded licks using a capacitance-based system. Subsequently, mice were maintained on ad libitum water, except for the night before exposure to a new concentration of sucrose to promote maximal consumption for habituation to the new taste. Mice were exposed daily to sucrose in the testing chamber in a number of conditions, and licking behavior was recorded for $30 \mathrm{~min}$. The order of exposure was $10 \%$ sucrose with water restriction ( 1 day), $10 \%$ sucrose with food restriction ( 2 days), and $10 \%$ sucrose sated ( 2 days). These conditions were then repeated in the same order with $2 \%$ sucrose. For food restricted conditions, mice were food deprived from the previous days' testing, and given $1 \mathrm{~h}$ free access to food following testing. For sated conditions, mice had ad lib access to food and water for at least $24 \mathrm{~h}$. Conditions were run for two consecutive days to measure stability of licking within each set of parameters. There were no differences between any 2 days within the same condition, so data was averaged across the 2 days for analysis. The number of licks over the whole session and lick rate for the first 2 min were analyzed. The first 2-min lick rate was used as a way to assess hedonic component of licking behavior without the influence of post-ingestion satiety-related factors (Davis 1973; Glendinning et al. 2002).

\section{Pavlovian-to-instrumental transfer}

Mice were tested in a modified Pavlovian-to-instrumental transfer protocol aimed at assessing the extent to which a Pavlovian conditioned stimulus (CS) can support the 
acquisition of a novel instrumental response, as previously described (O'Connor et al. 2010). All mice were first trained to retrieve an evaporated milk reward through head entry into the reward receptacle of the Med Associates chambers for 5 sessions. Mice were then trained for 12 sessions in a Pavlovian conditioning phase in which a cue (conditioned stimulus, CS) was paired with an evaporated milk reward. In each session, mice experienced $20 \mathrm{CS}+$ presentations $(10 \mathrm{~s}$ $10 \mathrm{~Hz}$ click or white noise) in which a dipper containing evaporated milk reward was presented for $5 \mathrm{~s}$ following the cue onset. In each session, mice also experienced 20 presentations of a CS - with which no reward was associated. CSs were presented in a pseudo-random order, with variable ITIs averaging $60 \mathrm{~s}$ (30-90 s range). The conditioned stimuli of either a click or white noise were counterbalanced across mice. The number of nosepokes into the reward receptacle was analyzed during $\mathrm{CS}+$ and $\mathrm{CS}-$ presentations for all sessions with the immediately preceding $10 \mathrm{~s}$ of ITI responding subtracted out (elevation score). There was no instrumental conditioning phase, and so the instrumental transfer test was performed on the day following the 12th Pavlovian conditioning session. In the transfer test session, mice were presented with two levers extended for $45 \mathrm{~min}$. A drop of evaporated milk reward was placed on each lever to promote lever pressing. Lever presses resulted in a 3-s presentation of either the CS + or CS - , but no reward was presented. The CS paired with the left or right lever was counterbalanced across mice and CS type. The number of presses to each lever was recorded, and grouped by association with $\mathrm{CS}+$ or CS - across mice. The difference score (CS + minus $\mathrm{CS}-$ lever presses) was calculated for each mouse.

\section{Variable value Go/No-Go paradigm}

To assess the effect of reward value on impulsive action, we developed a novel paradigm based on the Go/No-Go Test of impulsive action. Mice were trained as described in Operant Behavioral Training, except CRF training took place with both levers extended such that pressing either lever provided reward. All mice initially sampled each lever. For the validation study, training continued for 6 days, by which point all mice had formed stable and strongly biased lever preferences, which was determined based on average percentage of presses during the final three days of CRF training (range 77 to $100 \%)$. For the experimental study, training continued for 7 days, with 3 mice being excluded from future testing due to not acquiring lever pressing behavior. The remaining mice again formed biased lever preferences (range 61 to $100 \%)$. In order to cause a reversal of their preference, the less preferred lever was then rewarded with three times the amount of evaporated milk reward compared to the more preferred lever, which remained at $0.02 \mathrm{ml}$ evaporated milk. In order to deliver the larger, $0.06 \mathrm{ml}$ reward, the dipper was activated three times in short succession, as previously described. In these reversal sessions, mice were presented with 10 forced choice trials ( 5 per lever) in which only one lever was extended until the lever was pressed (requiring them to sample each lever), followed by 20 choice trials in which both levers were presented. Mice were required to reach a criterion of $25 \%$ choice for the higher reward lever (averaged over the final 3 days of training) in order to be included in future testing. After 14 sessions, mice in the validation study were choosing the high reward lever $69 \pm 6 \%$ of the time (averaged over the final 3 days of training). In the experimental study, 3 mice failed to reach the $25 \%$ criterion and were removed. With this exclusion, mice chose the higher reward lever $57 \pm 3 \%$ of the time (averaged over the final 3 days of training). Sixty trials were presented in each session, with 30 trials presented on each of the large and small reward levers randomly in blocks of 10 trials. In all trials, the lever extended for $5 \mathrm{~s}$. A press within $5 \mathrm{~s}$ initiated reward delivery, and lever retraction ("Successful Go Trial"). Otherwise, the lever retracted after $5 \mathrm{~s}$ and no reward was delivered ("Unsuccessful Go Trial"). Finally, mice were exposed to 8 sessions in which No-Go trials were added such that there were 16 Go and 16 No-Go trials on each lever (64 total trials/session). In No-Go trials, the lever was presented simultaneously with 2 cues (the house lights turning off, and a small LED light above the lever turning on). A lever press during the 5-s trial caused the lever to retract, the house lights to turn on, the LED light to turn off, and a new ITI to begin without any reward for that trial ("Unsuccessful No-Go Trial"). A lack of presses during the 5-s trial resulted in a reward presentation ("Successful No-Go Trial"). Hit rate was calculated as the proportion of Successful Go trials and the false alarm rate as the proportion of Unsuccessful No-Go trials, respectively averaged over all days. Impulsivity index was calculated for small and large reward levers by subtracting the proportion of correct No-Go trials from the proportion of correct Go trials. This composite index has a maximum score of +1 , which indicates highest impulsive responding (always responding on Go and No-Go trials). The minimum score of -1 indicates lowest impulsive behavior, essentially never responding on either No-Go or Go trials. The latency to lever press was also recorded for each trial and averaged across days; the latency was recorded as the maximum $5 \mathrm{~s}$ if there was no lever press during the trial.

\section{Statistical analysis}

Group effects were evaluated using analysis of variance (ANOVA), with post hoc Fisher's PLSD in StatView (SAS Software, Cary, NC) or SPSS (IBM, Armonk, NY). When pairwise comparisons were made following the primary ANOVAs, one-way ANOVAs were first used to test 
group effects within conditions when there was a significant interaction in the repeated measures ANOVAs, followed by post hoc Fisher's LSD if there was an effect of $5-\mathrm{HT}_{1 \mathrm{~B}} \mathrm{R}$ expression. Two-way repeated measures ANOVAs were used to assess the effects of $5-\mathrm{HT}_{1 \mathrm{~B}} \mathrm{R}$ (control, no expression, rescued expression) on concurrent choice and devaluation $\left(5-\mathrm{HT}_{1 \mathrm{~B}} \mathrm{R}\right.$ expression $\mathrm{x}$ condition [evaporated milk or standard chow]), random ratio $\left(5-\mathrm{HT}_{1 \mathrm{~B}} \mathrm{R}\right.$ expression $\times \mathrm{RR}$ schedule), progressive ratio $\left(5-\mathrm{HT}_{1 \mathrm{~B}} \mathrm{R}\right.$ expression $\times 3$ days), and extinction $\left(5-\mathrm{HT}_{1 \mathrm{~B}} \mathrm{R}\right.$ expression $\times 3$ days). For all remaining experiments, $5-\mathrm{HT}_{1 \mathrm{~B}} \mathrm{R}$ expression levels only included whole life knockout and control. Two-way repeated measures ANOVAs were also used for the standard Go/No-Go $\left(5-\mathrm{HT}_{1 \mathrm{~B}} \mathrm{R}\right.$ expression $\times 10$ days), delay discounting $\left(5-\mathrm{HT}_{1 \mathrm{~B}} \mathrm{R}\right.$ expression $\times$ delay), and effort discounting $\left(5-\mathrm{HT}_{1 \mathrm{~B}} \mathrm{R}\right.$ expression $\times$ FR schedule). For delay discounting, a linear equation was also fit to data from each mouse. The slope, intercept, and fit $\left(r^{2}\right)$ were compared between groups using unpaired $t$-tests. The indifference point, defined as the time delay when the preference was $50 \%$ was calculated for each mouse based on the linear equation, and compared between groups using an unpaired $t$-test. For the lickometer tests of hedonic value/reward reactivity, threeway mixed ANOVAs were used to determine the effects of $5-\mathrm{HT}_{1 \mathrm{~B}} \mathrm{R}$ expression, sucrose concentration, and fed state (restricted or sated). A two-way mixed ANOVA was used to analyze the effect of CS and genotype on nose poking during the Pavlovian training in the PIT paradigm, and an unpaired $t$-test was used to compare the difference score between genotypes on the instrumental transfer test. Two-way mixed ANOVAs were used for the effect of reward value on impulsivity in the Variable Value Go/ No-Go paradigm validation study (reward size $\times 10$ days for impulsivity index; reward size $\times$ trial type for hit rate/ false alarm rate and latencies). Three-way mixed ANOVAs were used to assess the effect of reward value and $5-\mathrm{HT}_{1 \mathrm{~B}} \mathrm{R}$ expression manipulation on impulsivity in the experimental Variable Value Go/No-Go paradigm $\left(5-\mathrm{HT}_{1 \mathrm{~B}} \mathrm{R}\right.$ expression $\times$ reward size $\times 10$ days for impulsivity index; $5-\mathrm{HT}_{1 \mathrm{~B}} \mathrm{R}$ expression $\times$ reward size $\times$ trial type for hit rate/ false alarm rate and latencies). Mixed ANOVAs, as appropriate, were also used to assess the interaction of sex with these variables. For food consumption, sex was found to have a significant effect; therefore, data was analyzed with a three-way mixed ANOVA for the effects of 5-HT ${ }_{1 \mathrm{~B}} \mathrm{R}$ expression, time, and sex in the restricted condition, and a two-way ANOVA for the effects of $5-\mathrm{HT}_{1 \mathrm{~B}} \mathrm{R}$ expression and sex in the sated condition. There were no significant effects of sex on the remaining behaviors measured, and therefore, the sexes are combined for all other analyses presented.

\section{Results}

Mice lacking 5- $\mathrm{HT}_{1 \mathrm{~B}} \mathrm{R}$ expression showed increased responding on operant lever pressing including on random ratio and progressive ratio schedules, which was also interestingly reversed by adult rescue of receptor expression. For random ratio schedules, 5- $\mathrm{HT}_{1 \mathrm{~B}} \mathrm{R}$ influenced the number of presses-mice lacking $5-\mathrm{HT}_{1 \mathrm{~B}} \mathrm{R}$ expression pressed 40-50\% more than control and adult rescue mice (Fig. 1A; $\left.F_{2,55}=8.0, p=0.0009\right)$. As the effort requirements increased, the effect of $5-\mathrm{HT}_{1 \mathrm{~B}} \mathrm{R}$ expression on lever pressing became larger $\left(F_{4,110}=3.4, p=0.0118\right.$ for interaction; $F_{2,110}=182.4$, $p<0.0001$ for main effect of schedule). This suggests that the increased responding is related to goal-directed or motivated responding, rather than a general increase in activity which would likely be read out as increased responding equivalently across all schedules. Adult rescue of receptor expression rescued normal behavior which points to an online adult rather than developmental or compensatory mechanism of action (all post hoc $p>0.05$ for all schedules for adult rescue vs. controls).

To assess motivation, we used a progressive ratio ( $\mathrm{PR} \times 2)$ schedule of responding and found that the absence of 5 - $\mathrm{HT}_{1 \mathrm{~B}} \mathrm{R}$ increased lever pressing, which was also reversed by adult rescue (Fig. $1 \mathrm{~B} ; F_{2,53}=7.3, p=0.0016$ ). There were also significant effects of day $\left(F_{2,106}=70.1, p<0.0001\right)$ and $5-\mathrm{HT}_{1 \mathrm{~B}} \mathrm{R}$ expression $\times$ day interaction $\left(F_{4,106}=10.2\right.$, $p<0.0001)$. Curiously, the effect of 5-HT ${ }_{1 \mathrm{~B}} \mathrm{R}$ on lever pressing was only present on Day 1 (for post hoc comparisons of genotype, $F_{2,53}=12.0, p<0.0001 ; p<0.0001$ for control and $p=0.0008$ for adult rescue compared to $5-\mathrm{HT}_{1 \mathrm{~B}} \mathrm{R} \mathrm{KO}$, $p=0.4237$ for control vs. adult rescue), and not on Days 2 or $3\left(F_{2,53}<2.1, p>0.1378\right)$.

One interpretation of the increased responding on the first day, but not subsequent days of testing in the PR is that $5-\mathrm{HT}_{1 \mathrm{~B}} \mathrm{R} \mathrm{KO}$ mice show faster extinction resulting in lower responding after Day 1. To test this idea, we measured extinction of lever pressing behavior in non-rewarded sessions following RR-20 training. Over 3 days of extinction sessions, while all mice decreased lever pressing $\left(F_{2,110}=153.9, p<0.0001\right)$, there were no significant effects of 5- $\mathrm{HT}_{1 \mathrm{~B}} \mathrm{R}$ expression on number of lever presses (Fig. 1C; $F_{2,55}=1.5, p=0.2376$ for main effect of $5-\mathrm{HT}_{1 \mathrm{~B}} \mathrm{R}$ expression; $F_{4,110}=1.3, p=0.2705$ for interaction). The number of lever presses was also normalized to baseline lever pressing behavior to control for the higher starting point in mice lacking $5-\mathrm{HT}_{1 \mathrm{~B}} \mathrm{R}$ expression, and there were still no differences in extinction rates between groups (Fig. $1 \mathrm{D} ; F_{2,55}=1.6$, $p=0.2040$ for main effect of $5-\mathrm{HT}_{1 \mathrm{~B}} \mathrm{R}$ expression). This suggests that the behavioral pattern seen in the progressive ratio task is not due to differences in extinction rate. 
A

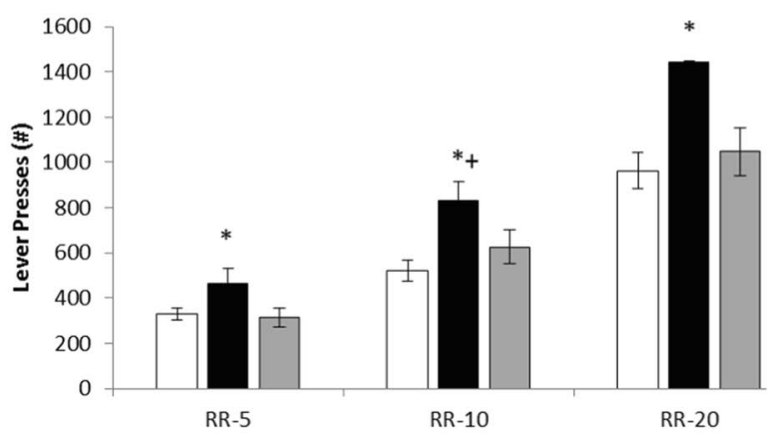

C

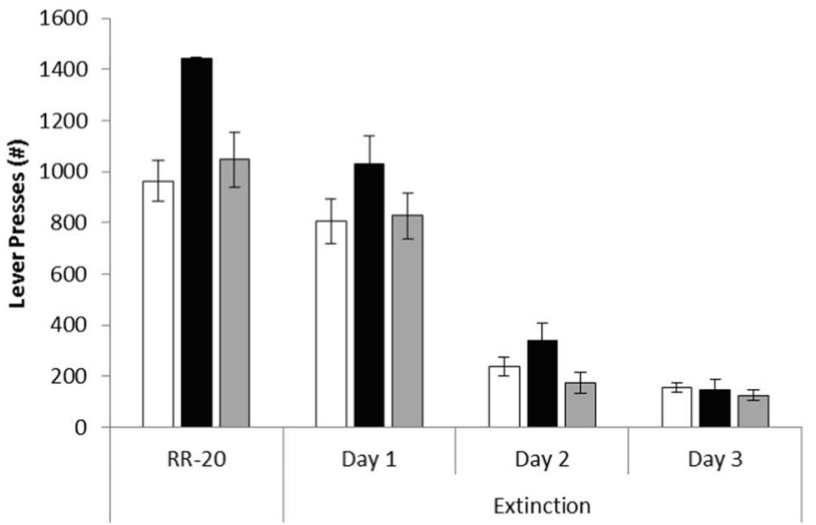

B

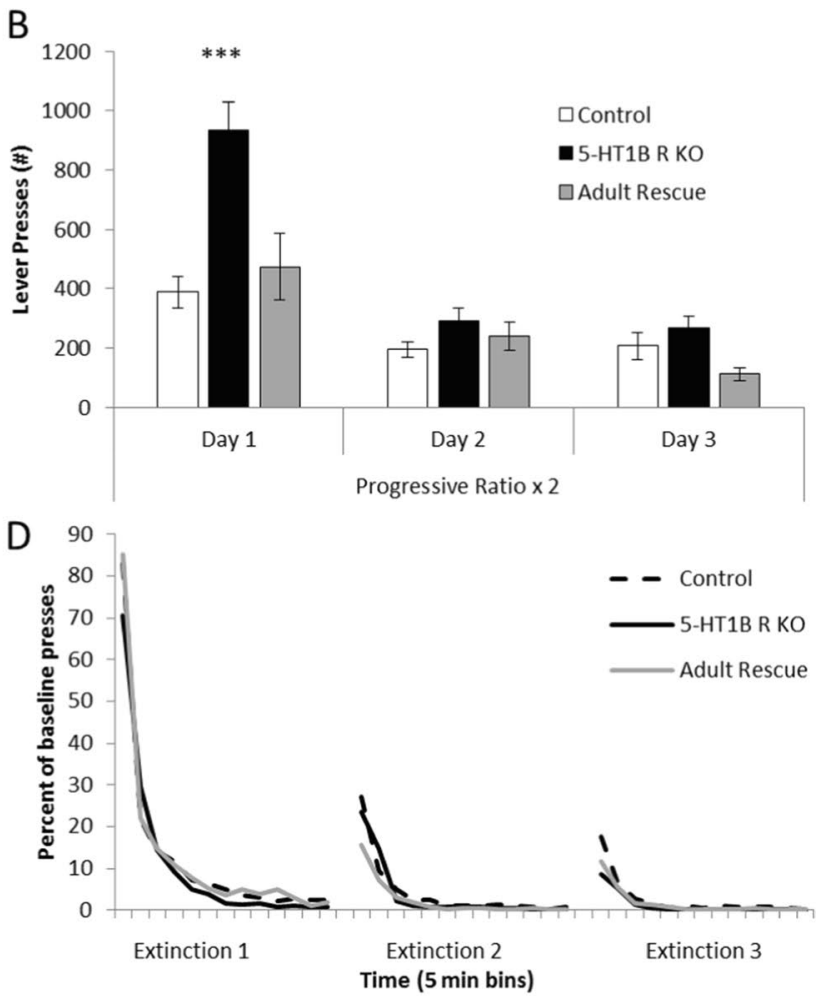

consecutive days. $* * * p<0.001$ and $p=0.0008$ for $5-\mathrm{HT}_{1 \mathrm{~B}} \mathrm{R} \mathrm{KO}$ compared to control and adult rescue groups. C Lever presses shown during 3 extinction sessions, compared to the previous RR-20 session. D Percentage of presses from RR-20 baseline, during 3 sessions of extinction trials, binned by $5 \mathrm{~min}$. All data shown are group means \pm SEM

more milk than food (Fig. 2B; $F_{2,55}=0.1, p=0.9187$ for main effect of $5-\mathrm{HT}_{1 \mathrm{~B}} \mathrm{R}$ expression; $F_{1,55}=325.8, p<0.0001$ for main effect of freely available option; $F_{2,55}=0.3$, $p=0.7535$ for interaction). Taken together, these results suggest that $5-\mathrm{HT}_{1 \mathrm{~B}} \mathrm{R}$ expression could influence either the representation of the outcome value that guides goal-directed action or habitual-like responding.

We first tested the hypothesis that mice lacking $5-\mathrm{HT}_{1 \mathrm{~B}} \mathrm{R}$ respond more habitually and are less guided by the outcome/goal of their actions. To do this, we measured goaldirected behavior following satiety-induced devaluation of the reward. There were no significant effects of $5-\mathrm{HT}_{1 \mathrm{~B}} \mathrm{R}$ expression in this test of habitual-like behavior. All mice similarly reduced responding when pre-fed with evaporated milk reward, but not when pre-fed with chow, showing that mice were responding in a similar goal-directed, rather than habitual manner on the RR-20 schedule (Fig. 2C; $F_{2,38}=0.1, p=0.8929$ for main effect of $5-\mathrm{HT}_{1 \mathrm{~B}} \mathrm{R}$ expression; $F_{1,38}=89.3, p<0.0001$ for main effect of prefed option; $F_{2,38}=2.1, p=0.1318$ for interaction). Furthermore, this suggests that the increased lever pressing behavior in 

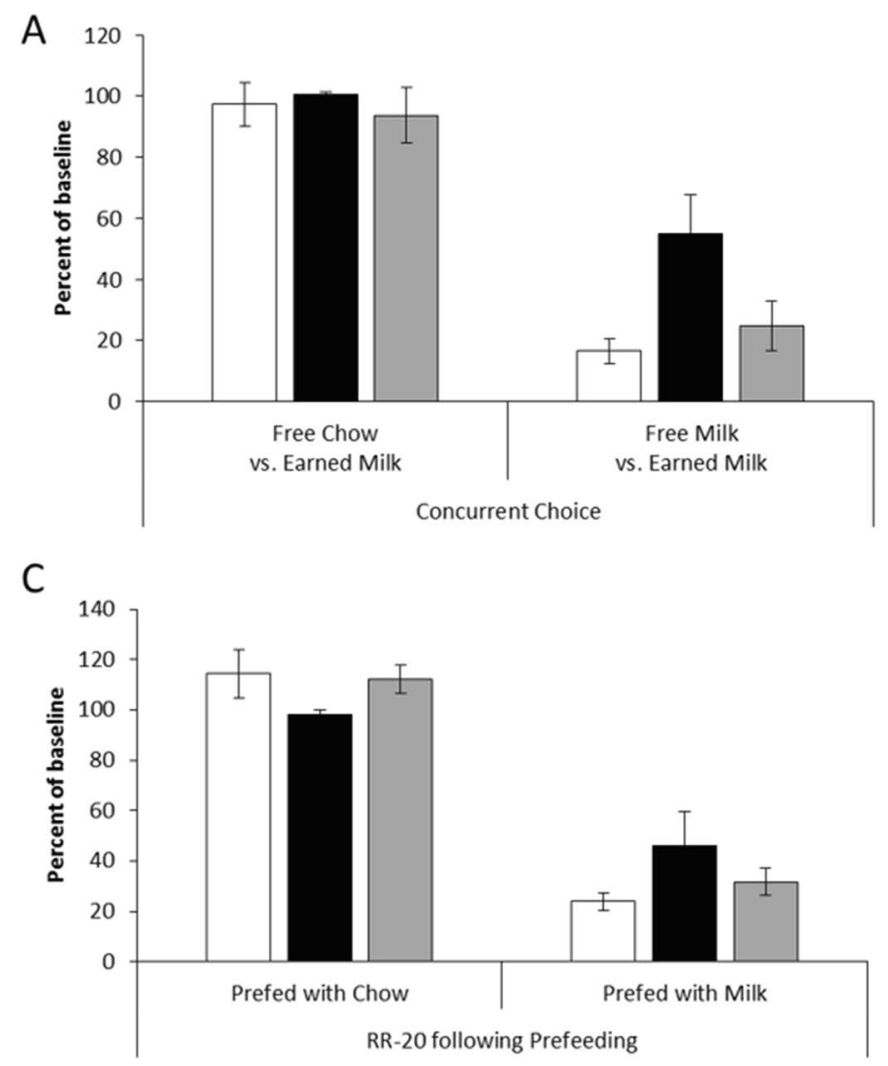

Fig. 2 Effects of 5-HT $1 \mathrm{~B}$ on habitual and goal-directed responding. A Lever presses are shown as a percentage of a total presses from a baseline RR-20 schedule in conditions in which chow or evaporated milk were presented as free alternatives to lever pressing for evaporated milk. B The amount of free alternative chow or evaporated milk that was consumed during the operant session is shown. $\mathbf{C}$ Lever presses are shown as a percentage of a total presses from a base-

mice lacking $5-\mathrm{HT}_{1 \mathrm{~B}} \mathrm{R}$ in the concurrent choice paradigm is likely not a function of increased habitual-like responding, but rather potentially due to altered representations of the reward value. This is also supported by an increased intake in the pre-operant test satiety induction with mice lacking $5-\mathrm{HT}_{1 \mathrm{~B}} \mathrm{R}$ expression consuming more reward in the pre-operant feeding sessions, with the increase being larger in the milk compared to the chow condition (Fig. 2D; $F_{2,38}=7.5, p=0.0018$ for main effect of $5-\mathrm{HT}_{1 \mathrm{~B}} \mathrm{R}$ expression; $F_{1,38}=343.9, p<0.0001$ for main effect of prefed option; $F_{2,38}=5.1, p=0.0106$ for interaction; for post hoc pairwise comparisons of genotype, all $p s>0.05$ for control vs. adult rescue, all $p s<0.05$ for $5-\mathrm{HT}_{1 \mathrm{~B}} \mathrm{R}$ vs. control and adult rescue). Overall these results suggest that the behavioral differences seen in mice lacking $5-\mathrm{HT}_{1 \mathrm{~B}} \mathrm{R}$ are not likely due to increased habitual-like responding.

As previously shown, a lack of $5-\mathrm{HT}_{1 \mathrm{~B}} \mathrm{R}$ expression increases impulsive action, but not impulsive choice. Specifically, mice lacking the $5-\mathrm{HT}_{1 \mathrm{~B}}$ receptor showed increased impulsive action in the Go/No-Go task (Fig. 3A), as
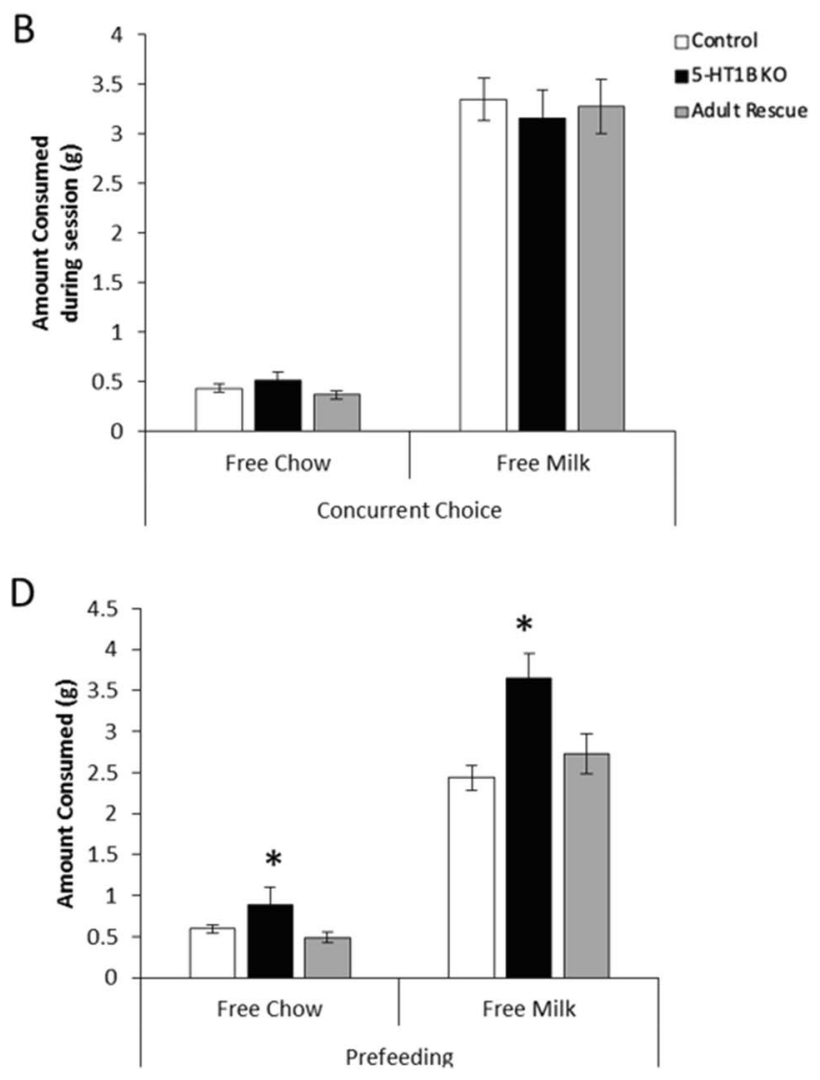

line RR-20 schedule in conditions in which mice were prefed chow or evaporated milk before the operant test session. D The amount of chow or evaporated milk that was consumed during the prefeeding session prior to operant session is shown. ${ }^{*} p<0.05,5-\mathrm{HT}_{1 \mathrm{~B}} \mathrm{R}$ $\mathrm{KO}$ compared to control and adult rescue groups. All data shown are group means \pm SEM

measured by a reduced ability to inhibit behavioral responding on No-Go trials $\left(F_{1,18}=7.0 p=0.0167\right)$. While they showed some improvement in their ability to inhibit level presses on No-Go trials over 10 training sessions, this was slower and reduced compared to control mice $\left(F_{9,162}=3.1\right.$, $p=0.0017$ for interaction; $F_{9,162}=8.1, p<0.0001$ for main effect of session). We also used a delay discounting paradigm as a second test of impulsivity aimed at measuring the impulsive choice dimension (Fig. 3B). There was a significant main effect of delay $\left(F_{5,85}=62.6, p<0.0001\right)$ as well as an effect of $5-\mathrm{HT}_{1 \mathrm{~B}} \mathrm{R}$ expression on preference for the large reward $\left(F_{1,17}=12.4, p=0.0026\right)$, with no interaction between $5-\mathrm{HT}_{1 \mathrm{~B}} \mathrm{R}$ expression and delay $\left(F_{5,85}=1.6\right.$, $p=0.1649)$. Therefore, interestingly, mice lacking 5- $\mathrm{HT}_{1 \mathrm{~B}} \mathrm{R}$ expression did not show increased choice impulsivity, but rather an overall increase in preference for the large reward. This is represented by an increased indifference point $\left(t_{17}=2.4, p=0.0281\right)$ - the delay length at which small immediate and large delayed rewards are chosen equally, $11.1 \mathrm{~s}( \pm 3.9 \mathrm{~s})$ in mice lacking $5-\mathrm{HT}_{1 \mathrm{~B}} \mathrm{R}$, compared to $2.5 \mathrm{~s}$ 


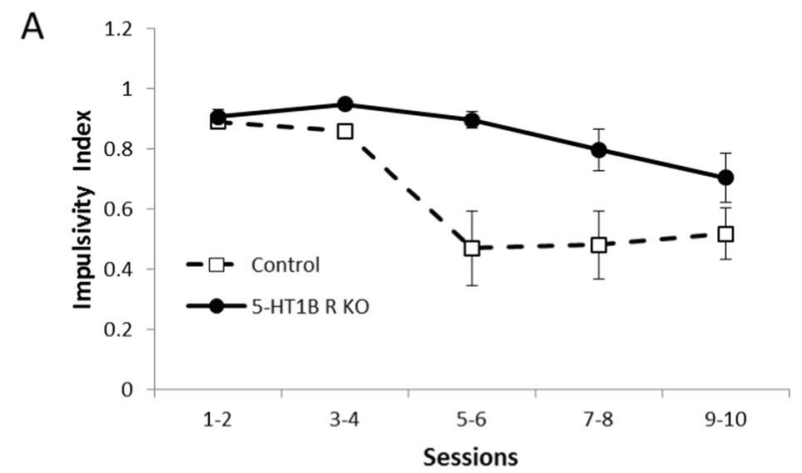

B
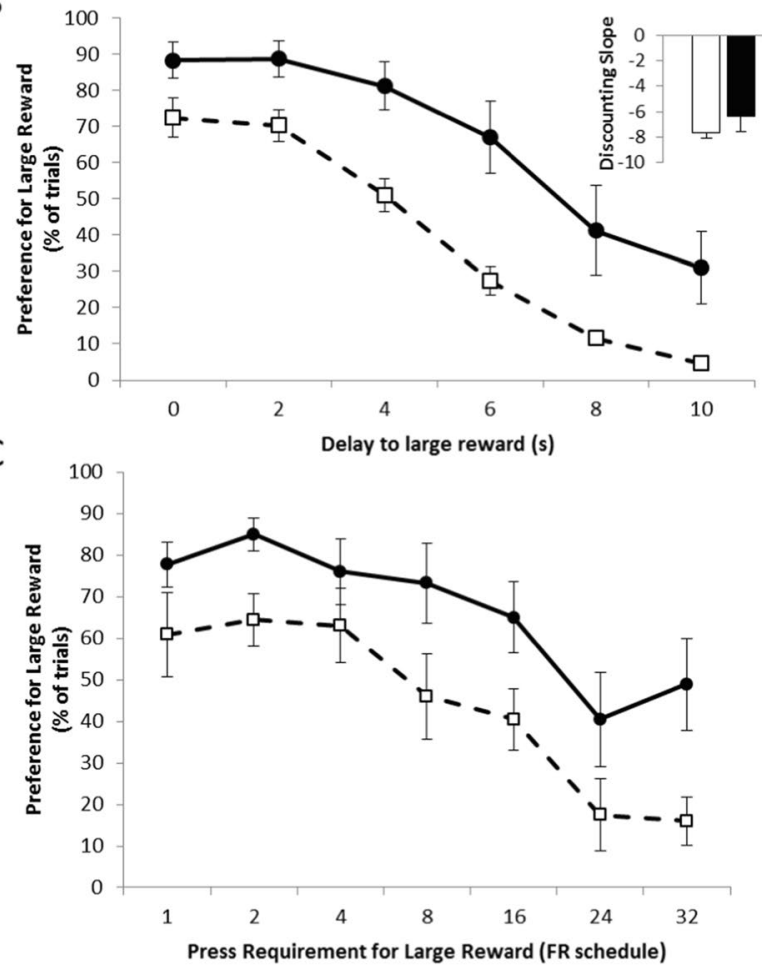

Fig. 3 Absence of 5- $\mathrm{HT}_{1 \mathrm{~B}} \mathrm{R}$ increases impulsive action but not delay or effort-based discounting. A Impulsivity index calculated as the proportion of successful Go trials minus the proportion of successful No-Go trials is shown as a measure of impulsive action (1.0 is the highest impulsivity that a mouse can display) over 10 days presented in 2-day bins. B Data from a delayed discounting paradigm are shown as the percentage of trials on which the large (delayed) reward was chosen, represented over delays ranging from 0 to $10 \mathrm{~s}$. Inset shows discounting slope, with more negative slopes indicating a more impulsive choice behavior. $\mathbf{C}$ Performance on an effort-based discounting task is shown for mice lacking $5-\mathrm{HT}_{1 \mathrm{~B}} \mathrm{R}$ and controls as a percentage of trials in which the large reward was chosen, represented over effort requirements ranging from fixed-ratio (FR)1 to FR32 schedules. All data are shown as group means \pm SEM

$( \pm 1.0 \mathrm{~s})$ in controls. However, the increased preference for the large reward was seen across all delays with no group differences in the slope of the discounting function $\left(t_{17}=1.1\right.$, $p=0.2991$ ), suggesting that the effect of $5-\mathrm{HT}_{1 \mathrm{~B}}$ is not on impulsivity. Rather, the overall increase in preference for the large reward across all delays is shown by an upward shift in the discounting curve $\left(t_{17}=2.0, p=0.0576\right.$ for trend toward change in intercept) suggesting that the effect of $5-\mathrm{HT}_{1 \mathrm{~B}} \mathrm{R}$ on choice may be due to changes in valuation of the reward.

To assess if the increased preference for the large reward was unique to delays or could be seen more generally in reward value-decision making, we tested the behavior of mice lacking $5-\mathrm{HT}_{1 \mathrm{~B}} \mathrm{R}$ in an effort-based discounting task. A similar pattern to the delay discounting data emergednamely that mice lacking $5-\mathrm{HT}_{1 \mathrm{~B}} \mathrm{R}$ expression showed increased preference for the large reward, over all effort requirements (Fig. 3C; $F_{1,17}=5.8, p=0.0273$ for main effect of $5-\mathrm{HT}_{1 \mathrm{~B}} \mathrm{R}$ expression; $F_{6,102}=19.9, p<0.0001$ for main effect of effort requirement; $F_{6,102}=0.6, p=0.6928$ for interaction). As seen in the delay discounting paradigm, there was no significant difference between groups in the slope of the discounting function $\left(t_{17}=0.9, p=0.3754\right)$, suggesting that the $5-\mathrm{HT}_{1 \mathrm{~B}} \mathrm{R}$ does not influence effort-based discounting, but rather might alter baseline reward value scaling.

Next, we addressed the hypothesis that an exaggerated representation of outcome value could arise from a difference in hedonic reactions to the reward. First, we measured amount of consumption to varied concentrations of evaporated milk reward used in operant tests (Fig S1). We found that mice lacking $5-\mathrm{HT}_{1 \mathrm{~B}} \mathrm{R}$ consume more evaporated milk than controls and increase their consumption as the reward concentration goes up, suggesting that they scale reward value differently $\left(F_{1,17}=5.9, p=0.027\right.$ for main effect of $5-\mathrm{HT}_{1 \mathrm{~B}} \mathrm{R}$ expression; $F_{2,34}=15.2, p<0.001$ for main effect of concentration; $F_{2,34}=4.4, p=0.020$ for interaction; for post hoc pairwise comparisons of genotype, $p<0.01$ at $66 \%$ milk concentration). Next, in order to test the effect of $5-\mathrm{HT}_{1 \mathrm{~B}} \mathrm{R}$ on hedonic value more directly, we used a standard lickometer to examine licking behavior to different concentrations of sucrose (Berridge and Robinson 2003; Dwyer 2012). The lickometer reduces some of the motivational components required for operant-based tasks, and also eliminates the contribution of post-ingestive factors found in consumption tests, therefore allowing measurement of a more immediate hedonic reaction through analysis of licking behavior. Mice lacking 5- $\mathrm{HT}_{1 \mathrm{~B}} \mathrm{R}$ expression showed overall increased in hedonic reactivity, as measured by increased licking for sucrose compared to controls (Fig. 4A,B; $F_{1,9}=12.0, p=0.007$ ). Across different conditions, mice lacking $5-\mathrm{HT}_{1 \mathrm{~B}} \mathrm{R}$ also showed greater increases in total licks as the motivational state or value increased suggesting that these mice were scaling reward value differently $\left(F_{1,9}=8.6, p=0.016\right.$ for interaction of $5-\mathrm{HT}_{1 \mathrm{~B}} \mathrm{R}$ expression $\times$ fed state; $F_{1,9}=4.8, p=0.056$ for suggestive interaction of $5-\mathrm{HT}_{1 \mathrm{~B}} \mathrm{R}$ expression $\mathrm{x}$ concentration). For all mice, there were main effects of deprivation state (food restricted vs. sated; $\left.F_{1,9}=89.9, p<0.001\right)$ and sucrose concentration ( $2 \%$ vs. $\left.10 \%, F_{1,9}=76.7, p<0.001\right)$, as well as a 
Fig. 4 - $\mathrm{HT}_{1 \mathrm{~B}} \mathrm{R}$ expression influences hedonic valuation. Total number of licks to a spout delivering sucrose, shown in food restricted (A) and sated (B) conditions to $2 \%$ and $10 \%$ sucrose. Lick rate in the first 2 min of the session, for food restricted (C) and sated (D) conditions to $2 \%$ and $10 \%$ sucrose. ${ }_{1}$ All data are shown as group means \pm SEM
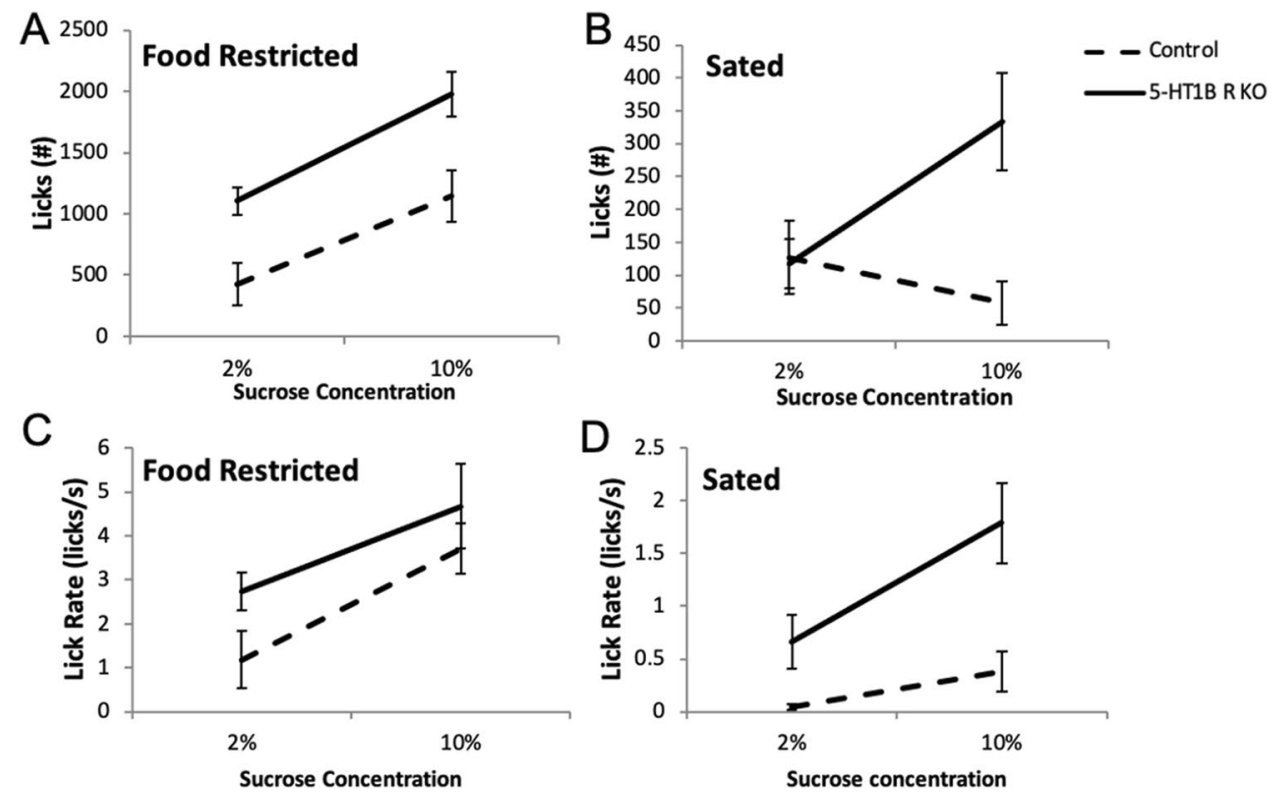

fed state $\times$ concentration $\left(F_{1,9}=85.9, p<0.001\right)$, with mice licking more in the restricted and $10 \%$ sucrose conditions. We also examined lick rate during the first 2 min of the sessions to remove any potential confound of effects of satiety on hedonic readouts since brief access durations reduce nontaste effects (Davis 1973; Glendinning et al. 2002). Again, all groups had increased lick rates toward $10 \%$ sucrose $\left(F_{1,9}=35.8, p<0.001\right.$ for main effect $)$ and in the restricted condition $\left(F_{1,9}=41.2, p<0.001\right.$ for main effect), with the increase being the largest in the restricted $10 \%$ condition $\left(F_{1,9}=11.5, p=0.008\right.$ for concentration $\times$ fed state interaction). Mice lacking 5-HT ${ }_{1 \mathrm{~B}} \mathrm{R}$ expression showed increased lick rates that approached significance (Fig. 4C,D; $F_{1,9}=4.3$, $p=0.069)$. Together, these results show that mice lacking $5-\mathrm{HT}_{1 \mathrm{~B}} \mathrm{R}$ expression have exaggerated licking responses compared to controls across all conditions, though importantly maintain the normal relative changes based on motivational state and concentration. This suggests that the absence of the $5-\mathrm{HT}_{1 \mathrm{~B}} \mathrm{R}$ acts to shift the scale of the normal valuation of reward.

We also addressed the possibility that the effects of $5-\mathrm{HT}_{1 \mathrm{~B}} \mathrm{R}$ expression were due to increased feeding drive rather than specific to reward responsivity. There were no significant differences in chow intake between $5-\mathrm{HT}_{1 \mathrm{~B}} \mathrm{R} \mathrm{KO}$ and littermate control mice in either restricted (Fig S2A; $F_{1,14}=0.4, p=0.555$ for $5-\mathrm{HT}_{1 \mathrm{~B}} \mathrm{R}$ expression; $F_{2,28}=0.3$, $p=0.758$ for $5-\mathrm{HT}_{1 \mathrm{~B}} \mathrm{R}$ expression $\times$ time interaction) or sated conditions (Fig S2B; $F_{1,14}=0.4, p=0.524$ ). All mice consume more food over longer periods of time in a deprived state $\left(F_{2,28}=463.8, p<0.001\right)$, with males consuming more in general and increasing with length of time $\left(F_{1,14}=10.3\right.$, $p=0.006$ for sex; $F_{2,28}=14.6, p<0.001$ for sex $\times$ time interaction). This effect of increased consumption in males also occurred in the 24-h sated period $\left(F_{1,14}=11.9, p=0.004\right)$. Importantly, there was no interaction of $5-\mathrm{HT}_{1 \mathrm{~B}} \mathrm{R}$ expression and sex in either experiment $\left(F_{1,14}=0.1, p=0.725\right.$ and $\left.F_{1,14}=0.1, p=0.725\right)$. These results suggest that the increase in reward-motivated behaviors seen in the absence of $5-\mathrm{HT}_{1 \mathrm{~B}} \mathrm{Rs}$ is not due to a general increase in hunger or feeding, and thus lends support to our interpretation that $5-\mathrm{HT}_{1 \mathrm{~B}} \mathrm{R}$ influences the valuation of palatable rewards.

So far, we have shown that mice lacking $5-\mathrm{HT}_{1 \mathrm{~B}} \mathrm{R}$ respond more vigorously to palatable rewards. We suggest that the exaggerated hedonic responses may be the result of higher value representations of reward, which also serve to increase goal-directed behavior relative to controls. We performed a modified Pavlovian-to-instrumental transfer (PIT) study to assess if a reward-paired cue motivates instrumental responding differently in the absence of $5-\mathrm{HT}_{1 \mathrm{~B}} \mathrm{R}$ expression. During the initial associative learning phase, all mice learned to discriminate between cues as measured by increased head entries into reward receptacle during the $\mathrm{CS}+$ compared to the $\mathrm{CS}-\left(\right.$ Fig. $5 \mathrm{~A} ; F_{11,132}=4.5$, $p<0.001$ for main effect of session; $F_{1,12}=10.6, p=0.007$ for main effect of CS type; $F_{11,132}=6.4, p<0.001$ for session $\times$ CS type interaction). There were no significant effects of genotype during the Pavlovian training phase $\left(F_{1,12}=0.8, p=0.401\right.$ for main effect; $F_{11,132}=0.5, p=0.922$ and $F_{1,12}=1.0, p=0.343$ for interaction of genotype with session or CS type, respectively; $F_{11,132}=0.7, p=0.709$ for genotype $\times$ session $\times$ CS type interaction). However, mice lacking $5-\mathrm{HT}_{1 \mathrm{~B}} \mathrm{R}$ expression displayed higher levels of lever pressing for the $\mathrm{CS}+$ in the instrumental transfer test compared to controls (Fig. 5B; $t_{12}=3.1, p=0.0107$ ). Importantly, the transfer test was performed in the absence of any prior instrumental training, highlighting the role of 

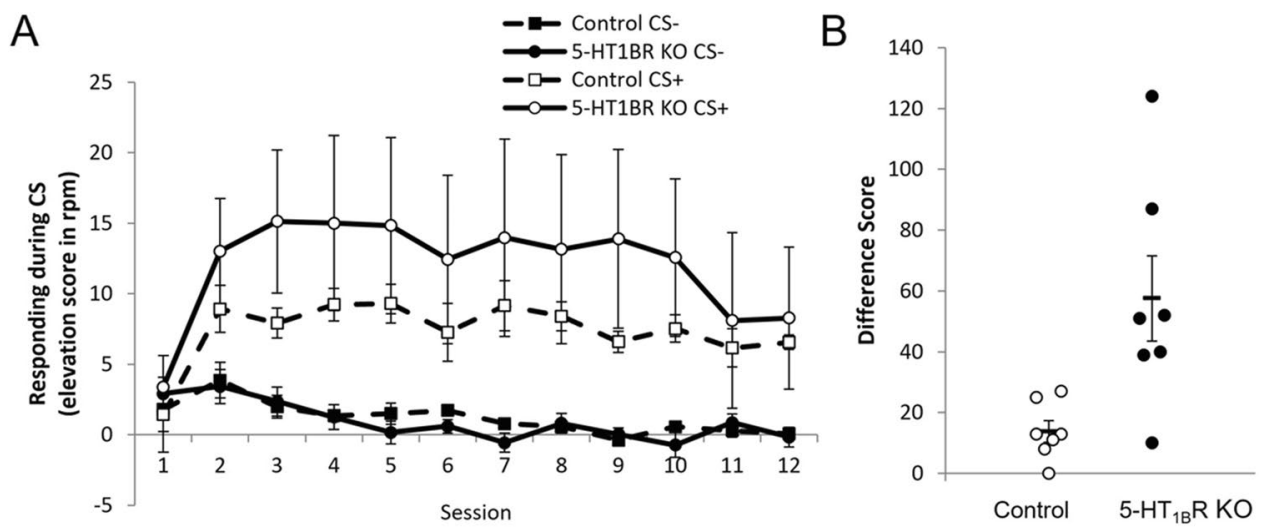

Fig. 5 Lack of 5-HT ${ }_{1 \mathrm{~B}} \mathrm{R}$ expression results in increased responding in a modified Pavlovian-to-instrumental transfer test. A Head entries into the reward receptacle are shown for 12 sessions of Pavlovian training represented as group means $( \pm$ SEM) of the increase in the number responses per minute (rpm) during the CS compared to rpm during $10 \mathrm{~s}$ of the ITI immediately preceding the CS. B Performance

the $\mathrm{CS}+$ in promoting acquisition of instrumental behavior, rather than a potentiation of a previously learned responseoutcome association. This suggests that the value attributed to the $\mathrm{CS}+$ motivates instrumental responding more in the absence of $5-\mathrm{HT}_{1 \mathrm{~B}} \mathrm{R}$ expression.

Given the effects of $5-\mathrm{HT}_{1 \mathrm{~B}}$ on driving reward associated cue-motivated behavior, we next tested if alterations in reward valuation could also explain the increased impulsivity seen in mice lacking $5-\mathrm{HT}_{1 \mathrm{~B}} \mathrm{R}$ expression. We first developed and tested a novel paradigm - the Variable Value Go/No-Go, to directly examine how manipulating reward value could impact impulsive action on a trial-by-trial basis (Fig. 6A). By varying reward value in a Go/No-Go paradigm within a single session, we could compare impulsivity within mice between trials in which large or small rewards were expected. In control mice, we found that mice were more impulsive on large compared to small reward trials (Fig S3; $F_{1,11}=19.1, p<0.001$ for main effect of reward size) which decreases over days $\left(F_{9,99}=7.0, p<0.001\right.$ for main effect of days; $F_{9,99}=2.2, p=0.025$ for interaction of reward $\times$ days). The increased impulsivity index in the large reward condition was influenced by both more correct Go trials and more incorrect No-Go trials $\left(F_{1,11}=19.1, p=0.001\right.$ for main effect of reward size), with faster responding on large reward trials $\left(F_{1,11}=9.5, p=0.010\right)$. Using this novel paradigm, we were then able to investigate the role of increased reward valuation in $5-\mathrm{HT}_{1 \mathrm{~B}} \mathrm{R}$-induced deficits in impulsive action, and test whether the increased impulsivity in mice lacking $5-\mathrm{HT}_{1 \mathrm{~B}} \mathrm{R}$ expression could be ameliorated by decreasing reward value. Our results show that the increased impulsivity in mice lacking $5-\mathrm{HT}_{1 \mathrm{~B}} \mathrm{R}$ was ameliorated, in part, by reducing the reward value by three times. Specifically, behavior on small reward trials in mice lacking $5-\mathrm{HT}_{1 \mathrm{~B}} \mathrm{R}$ on the instrumental transfer test is shown as the increase in the number of lever presses for the CS + over the number of lever presses for the $\mathrm{CS}-$ (difference score). Each animal is represented (open circle, controls; solid circle, $5-\mathrm{HT}_{1 \mathrm{~B}} \mathrm{R} \mathrm{KO}$ mice), as well as the group means $(-) \pm$ SEM

was similar to that of high reward trials in controls (Fig. 6B; $F_{1,16}=6.3, p=0.023$ for main effect of $5-\mathrm{HT}_{1 \mathrm{~B}} \mathrm{R}$ expression; $F_{1,16}=25.9, p<0.001$ for main effect of reward size). Overall, both a lack of $5-\mathrm{HT}_{1 \mathrm{~B}} \mathrm{R}$ expression and a larger reward magnitude increased impulsivity as seen in false alarm rates and hit rates (Fig. 6C,D; $F_{1,16}=6.3, p=0.023$ for main effect of 5-HT ${ }_{1 \mathrm{~B}} \mathrm{R}$ expression; $F_{1,16}=25.9, p<0.001$ for main effect of reward size). These effects could also be read out by decreased response latencies in mice lacking $5-\mathrm{HT}_{1 \mathrm{~B}} \mathrm{R}$ and in controls on large reward trials (Fig. 6E,F; $F_{1,16}=4.7, p=0.046$ for main effect of $5-\mathrm{HT}_{1 \mathrm{~B}} \mathrm{R}$ expression; $F_{1,16}=46.7, p<0.001$ for main effect of reward size). Interestingly, this shows that $5-\mathrm{HT}_{1 \mathrm{~B}} \mathrm{R}$-associated impulsivity can be reduced by decreasing the reward value and suggests that alterations in reward value alone can lead to increased impulsivity. Our data suggest that reward reactivity is an important behavioral component to measure in the study of the neural circuits underlying impulsivity, and point to a behavioral mechanism through which serotonin influences impulsive action.

\section{Discussion}

Overall, our data points to a role for altered reward value representation in the serotonin modulation of impulsive behavior. Specifically, we show that $5-\mathrm{HT}_{1 \mathrm{~B}} \mathrm{R}$ expression influences goal-directed behavior, motivation, PIT, and hedonic valuation, along with effects on impulsive action, but not impulsive choice. We also tested a subset of these phenotypes with adult rescue of $5-\mathrm{HT}_{1 \mathrm{~B}} \mathrm{R}$ expression which rescued normal behavior, suggesting ongoing modulation of neural circuits rather than compensatory effects. 

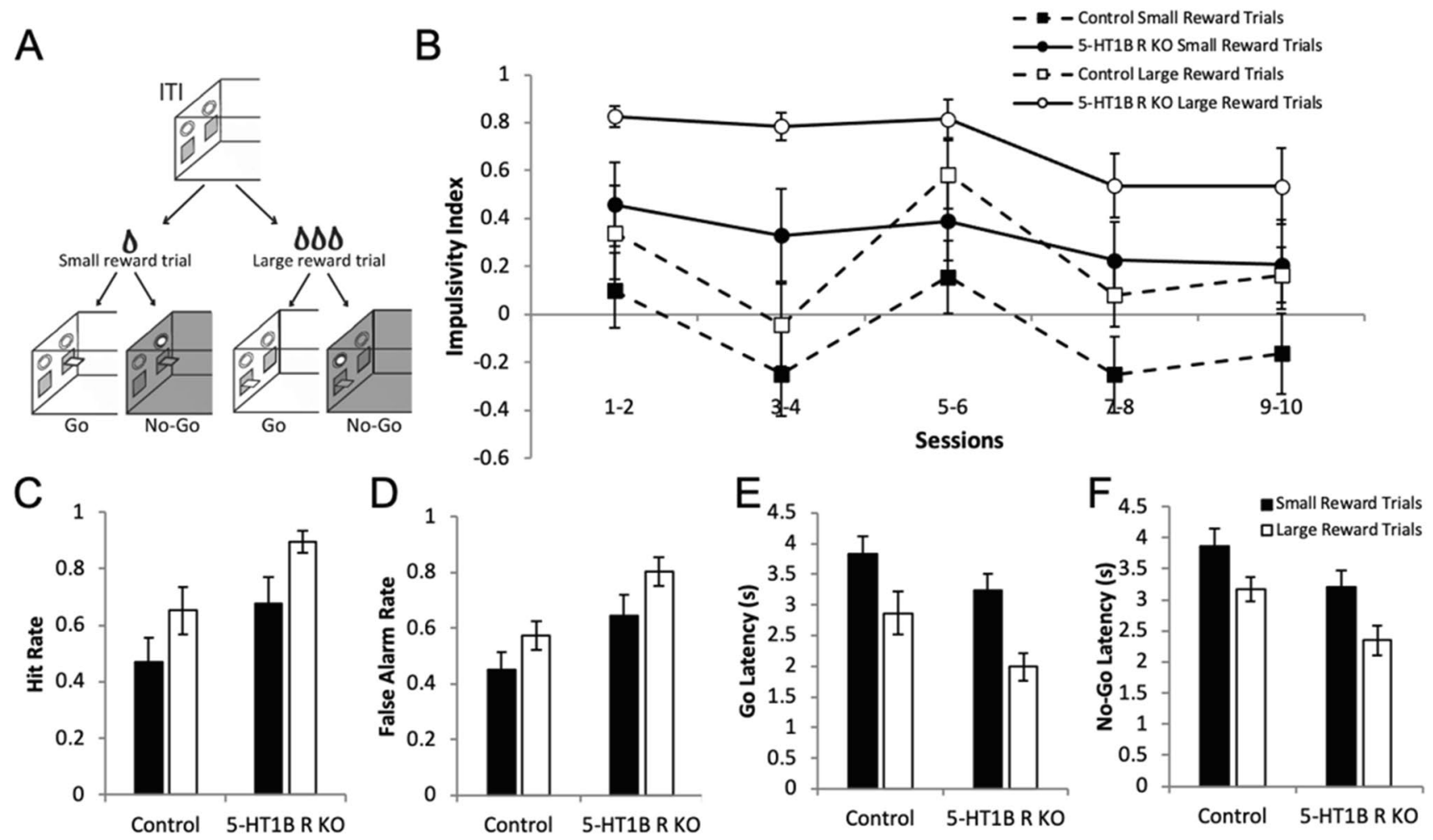

Fig. 6 Decreasing reward value ameliorates $5-\mathrm{HT}_{1 \mathrm{~B}} \mathrm{R}$-related impulsivity. A Diagram of Variable Value Go/No-Go paradigm. B Impulsivity index calculated as the proportion of successful Go trials minus the proportion of successful No-Go trials is shown as a measure of impulsive action (1.0 is the highest impulsivity that a mouse can dis-

While, we have previously shown that $5-\mathrm{HT}_{1 \mathrm{~B}} \mathrm{R}$ receptor expression influences impulsive action during adulthood, we now provide a behavioral mechanism of action. First, mice lacking 5- $\mathrm{HT}_{1 \mathrm{~B}} \mathrm{R}$ expression show increases in hedonic responses to sucrose, compared to controls. We propose that this may be a readout of increased valuation of rewards. This interpretation is consistent with a recent study which illustrates the influence of $5-\mathrm{HT}_{1 \mathrm{~B}} \mathrm{R}$ on the representation of outcomes through changes in sensitivity to the sensory qualities of reinforcers (Corbit et al. 2019). Interestingly, in our studies, mice lacking $5-\mathrm{HT}_{1 \mathrm{~B}} \mathrm{R}$ expression also show increased goal-directed responding, which is sensitive to extinction and devaluation, and we propose that this is driven by increased valuation of the reward. This is supported by increased responding seen in the PIT study in $5-\mathrm{HT}_{1 \mathrm{~B}} \mathrm{R} \mathrm{KO}$ mice, which suggests that a higher attribution of value to the $\mathrm{CS}+$ (acquired during the Pavlovian training) motivates higher levels of instrumental responding. Taken together with the effects of $5-\mathrm{HT}_{1 \mathrm{~B}} \mathrm{R}$ on impulsive action, these data point to the possibility that the influence of $5-\mathrm{HT}_{1 \mathrm{~B}} \mathrm{R}$ on reward valuation may contribute to the effects on goal-directed behavior and motivation, as well as on impulsive action.

play) over 10 days presented in 2-day bins. Data is shown for each small and large reward trials for controls and 5-HT ${ }_{1 \mathrm{~B}} \mathrm{R}$ KOs. C Hit rate for Go trials and $\mathbf{D}$ false alarm rate for No-Go trials. $\mathbf{E}$ Latency to press the lever for Go trials and for $\mathbf{F}$ No-Go trials. All data are shown as group means \pm SEM

Previous studies in humans and animal models have examined the relationship between hedonic value and impulsivity (Anker et al. 2008; Mechelmans et al. 2017; Weafer et al. 2014). In rats, increased sucrose-seeking is associated with increased impulsive action (measured in the 5-choice serial reaction time task) (Diergaarde et al. 2009), and rats bred for high sucrose consumption displayed higher levels of impulsive action (on the Go/No-Go task) when responding for cocaine (Anker et al. 2008), and also higher levels of impulsive choice (on the delay discounting task) (Perry et al. 2007). Though in humans, one study showed that increased hedonic value measured with varying sweet concentrations is associated with increases in impulsive choice (assessed in a delay discounting task), but not impulsive action (measured in a Go/No-Go paradigm) (Weafer et al. 2014). However, a confound in the interpretation of many of these studies suggesting associations between reward value and impulsivity arises from between-subjects designs measuring more trait-like phenotypes. This leaves open the possibility for another trait-level behavioral construct to mediate the association between reward value and impulsivity (e.g., learning about appetitive goal-directed behavioral contingencies). In order to test the causal association of higher 
valued incentive stimuli leading to increased impulsivity, we developed a within-subject, within-session experiment varying reward value, and could therefore directly measure the effects on impulsive action in the Go/No-Go task. The results from this Variable Value Go/No-Go paradigm show that increased reward value causes increased impulsive action as measured by a decrease in behavioral inhibition in No-Go trials. This supports a causal role for reward value in impulsive action. Furthermore, we were able to increase the impulsivity in controls to similar levels to that seen in mice lacking $5-\mathrm{HT}_{1 \mathrm{~B}} \mathrm{R}$ by tripling the reward value. This suggests that the impulsive phenotype seen in mice lacking $5-\mathrm{HT}_{1 \mathrm{~B}} \mathrm{R}$ could feasibly be derived by only changing the subjective value of the reward.

Given that past studies have implicated serotonin in the regulation of feeding and locomotion, alternative interpretations for our data include that the phenotypes are driven by an influence of 5- $\mathrm{HT}_{1 \mathrm{~B}} \mathrm{R}$ on increased hunger drive or general activity. To rule out hunger, we directly measured feeding behavior, and found no effect on food intake in fed or restricted conditions. Importantly, past work implicating $5-\mathrm{HT}_{1 \mathrm{~B}} \mathrm{R}$ in body weight regulation in the original $5-\mathrm{HT}_{1 \mathrm{~B}} \mathrm{R}$ knockout mouse line (generated in the 1980s) includes a methodological limitation of not controlling for genetic background (using non-congenic, non-littermate controls) making reported effects on bodyweight difficult to interpret (Bouwknecht et al. 2001b; Lee et al. 2004). Other pharmacology work has reported that $5-\mathrm{HT}_{1 \mathrm{~B}} \mathrm{R}$ agonists decrease food consumption; however, we suggest that these effects are derived from a non-specific behavioral effect on motivation, and because of the use of large doses that may bind non-specifically (Lee et al. 2004). For example, the authors report no effect on feeding at $5 \mathrm{mg} / \mathrm{kg}$ of the $5-\mathrm{HT}_{1 \mathrm{~B}} \mathrm{R}$ agonist CP-94,253, a dose that elicits behavioral effects on impulsivity, and report that the effects on food intake were only seen at doses more than twice at high $(10-20 \mathrm{mg} / \mathrm{kg})$. These higher doses also have suggestive or significant effects on feeding in $5-\mathrm{HT}_{1 \mathrm{~B}} \mathrm{R} \mathrm{KO}$ mice suggesting non-specific binding. Additionally, the idea that $5-\mathrm{HT}_{1 \mathrm{~B}} \mathrm{R}$ influences motivation for non-food reward is further supported by past studies showing increased motivation for cocaine in $5-\mathrm{HT}_{1 \mathrm{~B}} \mathrm{R} \mathrm{KO}$ mice (Rocha et al. 1998). To address the possibility that the reported phenotypes are due to hyperactivity, we also referenced past work in the $5-\mathrm{HT}_{1 \mathrm{~B}} \mathrm{R} \mathrm{KO}$ mouse. This past report of $5-\mathrm{HT}_{1 \mathrm{~B}} \mathrm{R}$ involvement in modulating a hyperactive response was specific to non-entrained stimuli (unexpected intruder in the resident-intruder task or disturbance by an experimenter) in a startle-like manner rather than a conditioned response to an entrained stimulus (Bouwknecht et al. 2001a). We would argue the unexpected and potentially stressful stimuli which induce the startle-like hyperactivity are unlike any stimuli presented in our studies. In fact, our data shows increased responding in a stimulus-free well-learned action-outcome contingency. Additionally, our results show that extinction and pre-feeding both reduce responding to control levels which would not be expected in a model of general hyperactivity. Based on these reports and our results, we maintain our initial interpretation that the behavioral effects seen here are not likely due to a change in feeding drive or activity, but rather an exaggeration of the representation of hedonic value of rewarding stimuli.

Past work has examined the role of $5-\mathrm{HT}_{1 \mathrm{~B}} \mathrm{R}$ in the modulation of a number of models of psychiatric disorders which present with reward-related dysfunctions including addiction and depression. However, there has been limited careful exploration of the underlying behavioral mechanisms that contribute to these $5-\mathrm{HT}_{1 \mathrm{~B}} \mathrm{R}$-associated phenotypes which is important for our understanding of complex behavioral processes found across multiple psychiatric disorders. Our data presents a basic reward reactivity-related phenotype that may serve as a framework for synthesizing these previously reported varied effects. Additionally, our work on behavioral mechanisms adds value to past and future studies investigating the neural circuit mechanisms through which $5-\mathrm{HT}_{1 \mathrm{~B}} \mathrm{R}$ exerts its effects on more complex phenotypes seen in substance use disorder and major depressive disorder.

Early studies in the original $5-\mathrm{HT}_{1 \mathrm{~B}} \mathrm{R}$ KO mouse line showed an increased motivation for (Castanon et al. 2000; Rocha et al. 1997, 1998) and decreased motivation for cocaine following 5- $\mathrm{HT}_{1 \mathrm{~B}}$ receptor agonist administration (Acosta et al. 2005), now we can investigate the circuit specific effects of 5- $\mathrm{HT}_{1 \mathrm{~B}} \mathrm{R}$ on drug taking behavior. We propose a role for $5-\mathrm{HT}_{1 \mathrm{~B}} \mathrm{Rs}$ expressed on the terminals of nucleus accumbens shell neurons, particularly in the rewarding properties of low-doses of cocaine that do not induce reward behavior in controls (Barot et al. 2007; Hoplight et al. 2007; Pentkowski et al. 2012). Additional work also implicates $5-\mathrm{HT}_{1 \mathrm{~B}} \mathrm{R}$ expression on these accumbens projection neurons in the consumption of ethanol (Furay et al. 2011). Alterations in ventral striatal $5-\mathrm{HT}_{1 \mathrm{~B}} \mathrm{R}$ expression are also seen in major depressive disorder (Murrough et al. 2011a, 2011b), and in rodents, 5-HT ${ }_{1 \mathrm{~B}} \mathrm{R}$ expression in the ventral striatum is implicated in inducing depressive states (Alexander et al. 2010; Svenningsson et al. 2006). Finally, the $5-\mathrm{HT}_{1 \mathrm{~B}} \mathrm{R}$ has also been examined in the context of social reward. Particularly, the rewarding properties of social behavior in mice requires activation of $5-\mathrm{HT}_{1 \mathrm{~B}} \mathrm{Rs}$ in the nucleus accumbens (Dolen et al. 2013). On one hand, these neural mechanisms point to a potential neural circuit mechanism for our results, and concurrently, our studies provide the behavioral mechanistic link between the circuit level mechanisms and the complex behavioral readouts.

It is interesting to note that the increasing reward value was associated with increased impulsive action, but not impulsive choice. Specifically, in the delay discounting task used to measure impulsive choice, mice lacking $5-\mathrm{HT}_{1 \mathrm{~B}} \mathrm{R}$ 
expression chose the large delayed reward more than controls across all delays. This increased preference was seen in trials without any delay, suggesting that the differences seen in the delay discounting task are not due to changes in the tolerance to delay, but rather to some factor that is common across all delays, such as reward valuation. This interpretation is consistent with past studies which have found that rats prone to attribute incentive salience to reward cues show increased impulsive action but not impulsive choice (Lovic et al. 2011). Though there is evidence that also supports a link between the sensitivity to the hedonic valuation of sweet reward and impulsive choice, it is possible that $5-\mathrm{HT}_{1 \mathrm{~B}} \mathrm{R}$ signaling acts through striatal mechanisms to link reward value and impulsive action rather than cortical areas like the vmPFC which may mediate the link between sweet taste activated reward and delay discounting (Rudenga and Small 2013; Sellitto et al. 2010; Weafer et al. 2014). This would fit with the lower relative levels of $5-\mathrm{HT}_{1 \mathrm{~B}} \mathrm{R}$ protein expression in the cortex compared to the ventral striatum (Boschert et al. 1994; Varnas et al. 2005). Indeed, a lack of $5-\mathrm{HT}_{1 \mathrm{~B}} \mathrm{R}$ expression results in increased dopamine release in the nucleus accumbens, which is a substrate for goalmotivated behaviors and impulsive action (Pecina and Berridge 2005; Pisansky et al. 2019; Sesia et al. 2008; Taha and Fields 2006). Understanding the 5- $\mathrm{HT}_{1 \mathrm{~B}} \mathrm{R}$-induced changes in reward reactivity that correlate with behavioral inhibition in impulsive action paradigms, but not temporal discounting in impulsive choice paradigms, may shed light on the neural circuits which underlie psychopathologies that have disordered reward responsiveness and impulsivity.

Overall, we propose that a behavioral mechanism for the effect of serotonin signaling on impulsive action is alterations in reward reactivity. While prior work demonstrated a role for $5-\mathrm{HT}_{1 \mathrm{~B}} \mathrm{R}$ expression in the modulation of impulsivity as well as the rewarding properties of drugs and social stimuli, our studies provide a unifying hypothesis for all of these effects by identifying a common underlying behavioral substrate. Specifically, we show that there is a causal effect of reward value on impulsive action in our novel Variable Value Go/No-Go paradigm and that decreasing reward value alone is enough to decrease $5-\mathrm{HT}_{1 \mathrm{~B}} \mathrm{R}$-associated impulsivity. These studies contribute to research aimed at understanding factors that contribute to increases in impulsivity seen in clinical populations. Additionally, our research points to the utility of serotonin receptor-specific treatment strategies to alter hedonic valuation for psychiatric disorders which involve dysregulated impulsivity.

Supplementary Information The online version contains supplementary material available at https://doi.org/10.1007/s00213-021-05944-2.

Acknowledgements We would like to thank Jun Ho Lee for lab management, Abigail Kalmbach for helpful assistance with the lickometer set-up, and Min Oh, Arati Sharma, and Anne George for help with data collection. We would also like to thank Professor Robert Leaton for his helpful comments on a previous version of this manuscript.

Author contribution SSD, EL, VMM, and $\mathrm{KN}$ acquired and managed the data. SSD, EL, and KN conducted data analysis. SSD and KN wrote the first draft of the paper. SSD, KN, and PB designed the studies. All authors contributed to and approved the final version of the paper.

Funding Funding was provided by NIH R00 MH106731 to KMN.

\section{Declarations}

Conflict of interest The authors declare no competing interests.

Open Access This article is licensed under a Creative Commons Attribution 4.0 International License, which permits use, sharing, adaptation, distribution and reproduction in any medium or format, as long as you give appropriate credit to the original author(s) and the source, provide a link to the Creative Commons licence, and indicate if changes were made. The images or other third party material in this article are included in the article's Creative Commons licence, unless indicated otherwise in a credit line to the material. If material is not included in the article's Creative Commons licence and your intended use is not permitted by statutory regulation or exceeds the permitted use, you will need to obtain permission directly from the copyright holder. To view a copy of this licence, visit http://creativecommons.org/licenses/by/4.0/.

\section{References}

Acosta JI, Boynton FA, Kirschner KF, Neisewander JL (2005) Stimulation of 5-HT1B receptors decreases cocaine- and sucrose-seeking behavior. Pharmacol Biochem Behav 80:297-307

Alexander B, Warner-Schmidt J, Eriksson T, Tamminga C, ArangoLievano M, Ghose S, Vernov M, Stavarache M, Musatov S, Flajolet M, Svenningsson P, Greengard P, Kaplitt MG (2010) Reversal of depressed behaviors in mice by 11 gene therapy in the nucleus accumbens. Science translational medicine 2:54ra76

Anker JJ, Gliddon LA, Carroll ME (2008) Impulsivity on a Go/No-go task for intravenous cocaine or food in male and female rats selectively bred for high and low saccharin intake. Behav Pharmacol 19:615-629

Balleine BW, Dickinson A (1998) The role of incentive learning in instrumental outcome revaluation by sensory-specific satiety. Anim Learn Behav 26:46-59

Bari A, Robbins TW (2013) Inhibition and impulsivity: behavioral and neural basis of response control. Prog Neurobiol 108:44-79

Barot SK, Ferguson SM, Neumaier JF (2007) 5-HT(1B) receptors in nucleus accumbens efferents enhance both rewarding and aversive effects of cocaine. Eur J Neurosci 25:3125-3131

Berridge KC, Robinson TE (2003) Parsing reward. Trends Neurosci 26:507-513

Berridge KC, Robinson TE (2016) Liking, wanting, and the incentivesensitization theory of addiction. Am Psychol 71:670-679

Berridge KC, Robinson TE, Aldridge JW (2009) Dissecting components of reward: 'liking', 'wanting', and learning. Curr Opin Pharmacol 9:65-73

Berridge KC, Venier IL, Robinson TE (1989) Taste reactivity analysis of 6-hydroxydopamine-induced aphagia: implications for arousal and anhedonia hypotheses of dopamine function. Behav Neurosci 103:36-45 
Boschert U, Amara DA, Segu L, Hen R (1994) The mouse 5-hydroxytryptamine1B receptor is localized predominantly on axon terminals. Neuroscience 58:167-182

Bouwknecht JA, Hijzen TH, van der Gugten J, Maes RA, Hen R, Olivier B (2001a) Absence of 5-HT(1B) receptors is associated with impaired impulse control in male 5-HT(1B) knockout mice. Biol Psychiat 49:557-568

Bouwknecht JA, van der Gugten J, Hijzen TH, Maes RA, Hen R, Olivier B (2001b) Male and female 5-HT(1B) receptor knockout mice have higher body weights than wildtypes. Physiol Behav 74:507-516

Brunner D, Hen R (1997) Insights into the neurobiology of impulsive behavior from serotonin receptor knockout mice. Ann N Y Acad Sci 836:81-105

Cao J, LaRocque E, Li D (2013) Associations of the 5-hydroxytryptamine (serotonin) receptor 1B gene (HTR1B) with alcohol, cocaine, and heroin abuse. Am J Med Genet B Neuropsychiatr Genet 162B:169-176

Castanon N, Scearce-Levie K, Lucas JJ, Rocha B, Hen R (2000) Modulation of the effects of cocaine by 5-HT1B receptors: a comparison of knockouts and antagonists. Pharmacol Biochem Behav 67:559-566

Chamorro J, Bernardi S, Potenza MN, Grant JE, Marsh R, Wang S, Blanco C (2012) Impulsivity in the general population: a national study. J Psychiatr Res 46:994-1001

Corbit L, Kendig M, Moul C (2019) The role of serotonin 1B in the representation of outcomes. Sci Rep 9:2497

Crane NA, Gorka SM, Weafer J, Langenecker SA, de Wit H, Phan KL (2018) Neural activation to monetary reward is associated with amphetamine reward sensitivity. Neuropsychopharmacology 43:1738-1744

Dalley JW, Everitt BJ, Robbins TW (2011) Impulsivity, compulsivity, and top-down cognitive control. Neuron 69:680-694

Dalley JW, Robbins TW (2017) Fractionating impulsivity: neuropsychiatric implications. Nat Rev Neurosci 18:158-171

Davis JD (1973) The effectiveness of some sugars in stimulating licking behavior in the rat. Physiol Behav 11:39-45

Dickinson A, Balleine B (1994) Motivational control of goal-directed action. Anim Learn Behav 22:1-18

Dickinson A, Balleine B (1995) Motivational control of instrumental action. Curr Dir Psychol Sci 4:162-167

Dickinson A, Balleine B (2002) The role of learning in the operation of motivational systems. In: Gallistel CR (ed) Stevens' handbook of experimental psychology: learning, motivation, and emotion, 3rd vol. Wiley and Sons, New York, pp 497-534

Diergaarde L, Pattij T, Nawijn L, Schoffelmeer AN, De Vries TJ (2009) Trait impulsivity predicts escalation of sucrose seeking and hypersensitivity to sucrose-associated stimuli. Behav Neurosci 123:794-803

Diergaarde L, Pattij T, Poortvliet I, Hogenboom F, de Vries W, Schoffelmeer AN, De Vries TJ (2008) Impulsive choice and impulsive action predict vulnerability to distinct stages of nicotine seeking in rats. Biol Psychiat 63:301-308

Dissabandara LO, Loxton NJ, Dias SR, Dodd PR, Daglish M, Stadlin A (2014) Dependent heroin use and associated risky behaviour: the role of rash impulsiveness and reward sensitivity. Addict Behav 39:71-76

Dolen G, Darvishzadeh A, Huang KW, Malenka RC (2013) Social reward requires coordinated activity of nucleus accumbens oxytocin and serotonin. Nature 501:179-184

Drew MR, Simpson EH, Kellendonk C, Herzberg WG, Lipatova O, Fairhurst S, Kandel ER, Malapani C, Balsam PD (2007) Transient overexpression of striatal $\mathrm{d} 2$ receptors impairs operant motivation and interval timing. J Neurosci 27:7731-7739
Dwyer DM (2012) EPS Prize Lecture. Licking and liking: the assessment of hedonic responses in rodents. Q J Exp Psychol 65:371-394

Ferland JM, Zeeb FD, Yu K, Kaur S, Taves MD, Winstanley CA (2014) Greater sensitivity to novelty in rats is associated with increased motor impulsivity following repeated exposure to a stimulating environment: implications for the etiology of impulse control deficits. Eur J Neurosci 40:3746-3756

Fletcher PJ, Tampakeras M, Sinyard J, Higgins GA (2007) Opposing effects of 5-HT(2A) and 5-HT(2C) receptor antagonists in the rat and mouse on premature responding in the five-choice serial reaction time test. Psychopharmacology 195:223-234

Furay AR, Neumaier JF, Mullenix AT, Kaiyala KK, Sandygren NK, Hoplight BJ (2011) Overexpression of 5-HT(1B) mRNA in nucleus accumbens shell projection neurons differentially affects microarchitecture of initiation and maintenance of ethanol consumption. Alcohol 45:19-32

Gaher RM, Hahn AM, Shishido H, Simons JS, Gaster S (2015) Associations between sensitivity to punishment, sensitivity to reward, and gambling. Addict Behav 42:180-184

Glendinning JI, Gresack J, Spector AC (2002) A high-throughput screening procedure for identifying mice with aberrant taste and oromotor function. Chem Senses 27:461-474

Higgins GA, Silenieks LB, Altherr EB, MacMillan C, Fletcher PJ, Pratt WE (2016) Lorcaserin and CP-809101 reduce motor impulsivity and reinstatement of food seeking behavior in male rats: implications for understanding the anti-obesity property of 5-HT2C receptor agonists. Psychopharmacology 233:2841-2856

Hoplight BJ, Vincow ES, Neumaier JF (2007) Cocaine increases 5-HT1B mRNA in rat nucleus accumbens shell neurons. Neuropharmacology 52:444-449

Jimenez-Murcia S, Fernandez-Aranda F, Mestre-Bach G, Granero R, Tarrega S, Torrubia R, Aymami N, Gomez-Pena M, Soriano-Mas C, Steward T, Moragas L, Bano M, Del Pino-Gutierrez A, Menchon JM (2017) Exploring the relationship between reward and punishment sensitivity and gambling disorder in a clinical sample: a path modeling analysis. J Gambl Stud 33:579-597

Jonker NC, Ostafin BD, Glashouwer KA, van Hemel-Ruiter ME, de Jong PJ (2014) Reward and punishment sensitivity and alcohol use: the moderating role of executive control. Addict Behav 39:945-948

Kamarajan C, Pandey AK, Chorlian DB, Manz N, Stimus AT, Bauer LO, Hesselbrock VM, Schuckit MA, Kuperman S, Kramer J, Porjesz B (2015) Reward processing deficits and impulsivity in high-risk offspring of alcoholics: a study of event-related potentials during a monetary gambling task. Int J Psychophysiol 98:182-200

Lee MD, Somerville EM, Kennett GA, Dourish CT, Clifton PG (2004) Reduced hypophagic effects of d-fenfluramine and the 5-HT2C receptor agonist mCPP in 5-HT1B receptor knockout mice. Psychopharmacology 176:39-49

Lovic V, Saunders BT, Yager LM, Robinson TE (2011) Rats prone to attribute incentive salience to reward cues are also prone to impulsive action. Behav Brain Res 223:255-261

MacKillop J, Weafer J, Gray JC, Oshri A, Palmer A, de Wit H (2016) The latent structure of impulsivity: impulsive choice, impulsive action, and impulsive personality traits. Psychopharmacology 233(18):3361-3370. https://doi.org/10.1007/s00213-016-4372-0

Matuskey D, Bhagwagar Z, Planeta B, Pittman B, Gallezot JD, Chen J, Wanyiri J, Najafzadeh S, Ropchan J, Geha P, Huang Y, Potenza MN, Neumeister A, Carson RE, Malison RT (2014) Reductions in brain 5-HT1B receptor availability in primarily cocaine-dependent humans. Biol Psychiat 76:816-822

Mechelmans DJ, Strelchuk D, Donamayor N, Banca P, Robbins TW, Baek K, Voon V (2017) Reward sensitivity and waiting 
impulsivity: shift towards reward valuation away from action control. Int J Neuropsychopharmacol 20:971-978

Moustafa AA, Tindle R, Frydecka D, Misiak B (2017) Impulsivity and its relationship with anxiety, depression and stress. Compr Psychiatry 74:173-179

Murrough JW, Czermak C, Henry S, Nabulsi N, Gallezot JD, Gueorguieva R, Planeta-Wilson B, Krystal JH, Neumaier JF, Huang Y, Ding YS, Carson RE, Neumeister A (2011a) The effect of early trauma exposure on serotonin type $1 \mathrm{~B}$ receptor expression revealed by reduced selective radioligand binding. Arch Gen Psychiatry 68:892-900

Murrough JW, Henry S, Hu J, Gallezot JD, Planeta-Wilson B, Neumaier JF, Neumeister A (2011b) Reduced ventral striatal/ventral pallidal serotonin1B receptor binding potential in major depressive disorder. Psychopharmacology 213:547-553

Nautiyal KM, Tanaka KF, Barr MM, Tritschler L, Le Dantec Y, David DJ, Gardier AM, Blanco C, Hen R, Ahmari SE (2015) Distinct circuits underlie the effects of 5-HT1B receptors on aggression and impulsivity. Neuron 86:813-826

Nautiyal KM, Wall MM, Wang S, Magalong VM, Ahmari SE, Balsam PD, Blanco C, Hen R (2017) Genetic and modeling approaches reveal distinct components of impulsive behavior. Neuropsychopharmacology 42:1182-1191

O'Connor EC, Stephens DN, Crombag HS (2010) Modeling appetitive Pavlovian-instrumental interactions in mice. Curr Protoc Neurosci 53:8.25.1-8.25.27

Ostlund SB, Kosheleff A, Maidment NT, Murphy NP (2013) Decreased consumption of sweet fluids in mu opioid receptor knockout mice: a microstructural analysis of licking behavior. Psychopharmacology 229:105-113

Pattij T, Broersen LM, van der Linde J, Groenink L, van der Gugten J, Maes RA, Olivier B (2003) Operant learning and differential-reinforcement-of-low-rate 36-s responding in 5-HT1A and 5-HT1B receptor knockout mice. Behav Brain Res 141:137-145

Pecina S, Berridge KC (2005) Hedonic hot spot in nucleus accumbens shell: where do mu-opioids cause increased hedonic impact of sweetness? J Neurosci 25:11777-11786

Pentkowski NS, Cheung TH, Toy WA, Adams MD, Neumaier JF, Neisewander JL (2012) Protracted withdrawal from cocaine selfadministration flips the switch on 5-HT(1B) receptor modulation of cocaine abuse-related behaviors. Biol Psychiat 72:396-404

Perry JL, Nelson SE, Anderson MM, Morgan AD, Carroll ME (2007) Impulsivity (delay discounting) for food and cocaine in male and female rats selectively bred for high and low saccharin intake. Pharmacol Biochem Behav 86:822-837

Pisansky MT, Lefevre EM, Retzlaff CL, Trieu BH, Leipold DW, Rothwell PE (2019) Nucleus accumbens fast-spiking interneurons constrain impulsive action. Biol Psychiat 86:836-847

Potenza MN, Walderhaug E, Henry S, Gallezot JD, Planeta-Wilson B, Ropchan J, Neumeister A (2013) Serotonin 1B receptor imaging in pathological gambling. World J Biol Psychiatry 14:139-145

Robbins TW, Gillan CM, Smith DG, de Wit S, Ersche KD (2012) Neurocognitive endophenotypes of impulsivity and compulsivity: towards dimensional psychiatry. Trends Cogn Sci 16:81-91

Rocha BA, Ator R, Emmett-Oglesby MW, Hen R (1997) Intravenous cocaine self-administration in mice lacking 5-HT1B receptors. Pharmacol Biochem Behav 57:407-412

Rocha BA, Scearce-Levie K, Lucas JJ, Hiroi N, Castanon N, Crabbe JC, Nestler EJ, Hen R (1998) Increased vulnerability to cocaine in mice lacking the serotonin-1B receptor. Nature 393:175-178

Rudenga KJ, Small DM (2013) Ventromedial prefrontal cortex response to concentrated sucrose reflects liking rather than sweet quality coding. Chem Senses 38:585-594
Sellitto M, Ciaramelli E, di Pellegrino G (2010) Myopic discounting of future rewards after medial orbitofrontal damage in humans. J Neurosci 30:16429-16436

Sesia T, Temel Y, Lim LW, Blokland A, Steinbusch HW, Visser-Vandewalle V (2008) Deep brain stimulation of the nucleus accumbens core and shell: opposite effects on impulsive action. Exp Neurol 214:135-139

Smith KS, Berridge KC (2007) Opioid limbic circuit for reward: interaction between hedonic hotspots of nucleus accumbens and ventral pallidum. The Journal of Neuroscience : the Official Journal of the Society for Neuroscience 27:1594-1605

Strickland JC, Johnson MW (2020) Rejecting impulsivity as a psychological construct: a theoretical, empirical, and sociocultural argument. Psychol Rev 128:336-361

Svenningsson P, Chergui K, Rachleff I, Flajolet M, Zhang X, El Yacoubi M, Vaugeois JM, Nomikos GG, Greengard P (2006) Alterations in 5-HT1B receptor function by p11 in depressionlike states. Science 311:77-80

Taha SA, Fields HL (2006) Inhibitions of nucleus accumbens neurons encode a gating signal for reward-directed behavior. J Neurosci 26:217-222

Varnas K, Hurd YL, Hall H (2005) Regional expression of 5-HT1B receptor mRNA in the human brain. Synapse 56:21-28

Verdejo-García A, Lawrence AJ, Clark L (2008) Impulsivity as a vulnerability marker for substance-use disorders: review of findings from high-risk research, problem gamblers and genetic association studies. Neurosci Biobehav Rev 32:777-810

Ward RD, Simpson EH, Richards VL, Deo G, Taylor K, Glendinning JI, Kandel ER, Balsam PD (2012) Dissociation of hedonic reaction to reward and incentive motivation in an animal model of the negative symptoms of schizophrenia. Neuropsychopharmacology 37:1699-1707

Weafer J, Burkhardt A, de Wit H (2014) Sweet taste liking is associated with impulsive behaviors in humans. Front Behav Neurosci 8:228

Winstanley CA, Dalley JW, Theobald DE, Robbins TW (2004a) Fractionating impulsivity: contrasting effects of central 5-HT depletion on different measures of impulsive behavior. Neuropsychopharmacology 29:1331-1343

Winstanley CA, Theobald DE, Dalley JW, Glennon JC, Robbins TW (2004b) 5-HT2A and 5-HT2C receptor antagonists have opposing effects on a measure of impulsivity: interactions with global 5-HT depletion. Psychopharmacology 176:376-385

Worbe Y, Savulich G, Voon V, Fernandez-Egea E, Robbins TW (2014) Serotonin depletion induces 'waiting impulsivity' on the human four choice serial reaction time task: cross-species translational significance. Neuropsychopharmacology 39:1519-1526

Zeeb FD, Soko AD, Ji X, Fletcher PJ (2016) Low impulsive action, but not impulsive choice, predicts greater conditioned reinforcer salience and augmented nucleus accumbens dopamine release. Neuropsychopharmacology 41:2091-2100

Zeeb FD, Wong AC, Winstanley CA (2013) Differential effects of environmental enrichment, social-housing, and isolation-rearing on a rat gambling task: dissociations between impulsive action and risky decision-making. Psychopharmacology 225:381-395

Publisher's note Springer Nature remains neutral with regard to jurisdictional claims in published maps and institutional affiliations. 